Published in final edited form as:

Chem Res Toxicol. 2016 February 15; 29(2): 213-226. doi:10.1021/acs.chemrestox.5b00484.

\title{
Conformational Insights into the Mechanism of Acetylaminofluorene-dG-Induced Frameshift Mutations in the Nart Mutational Hotspot
}

\author{
Lifang Xu, Bongsup P. Cho* \\ Department of Biomedical and Pharmaceutical Sciences, College of Pharmacy, University of \\ Rhode Island, Kingston, Rhode Island 02881, United States
}

\begin{abstract}
Frameshift mutagenesis encompasses the gain or loss of DNA base pairs, resulting in altered genetic outcomes. The $N a r t$ restriction site sequence $5^{\prime}-\mathrm{G}_{1} \mathrm{G}_{2} \mathrm{CG}_{3} \mathrm{CX}-3^{\prime}$ in Escherichia coli is a well-known mutational hotspot, in which lesioning of acetylaminofluorene (AAF) at $\mathrm{G}_{3}$ * induces a greater -2 deletion frequency than that at other guanine sites. Its mutational efficiency is modulated by the nature of the nucleotide in the $X$ position $(\mathrm{C} \sim \mathrm{A}>\mathrm{G} \gg \mathrm{T})$. Here, we conducted a series of polymerase-free solution experiments that examine the conformational and thermodynamic basis underlying the propensity of adducted $\mathrm{G}_{3}$ to form a slipped mutagenic intermediate (SMI) and its sequence dependence during translesion synthesis (TLS). Instability of the $A A F-\mathrm{dG}_{3}: \mathrm{dC}$ pair at the replication fork promoted slippage to form a $\mathrm{G}^{*} \mathrm{C}$ bulge-out SMI structure, consisting of S- ("lesion stacked") and B-SMI ("lesion exposed") conformations, with conformational rigidity increasing as a function of primer elongation. We found greater stability of the S- compared to the B-SMI conformer throughout TLS. The dependence of their population ratios was determined by the $3^{\prime}$-next flanking base $X$ at fully elongated bulge structures, with 59\% $\mathrm{B} / 41 \% \mathrm{~S}$ and $86 \% \mathrm{~B} / 14 \% \mathrm{~S}$ for the $\mathrm{dC}$ and $\mathrm{dT}$ series, respectively. These results indicate the importance of direct interactions of the hydrophobic AAF lesion with the $3^{\prime}$-next flanking base pair and its stacking fit within the -2 bulge structure. A detailed conformational understanding of the SMI structures and their sequence dependence may provide a useful model for DNA polymerase complexes.
\end{abstract}

\section{Graphical Abstract}

\footnotetext{
*Corresponding Author Phone: +1 401874 5024. bcho@uri.edu.

The authors declare no competing financial interest. ASSOCIATED CONTENT

Supporting Information

The Supporting Information is available free of charge on the ACS Publications website at DOI: 10.1021/acs.chemrestox.5b00484. HPLC profile comparison; MALDI-TOF characterization of dC peak 2, dC peak 1, dC peak 3, dT peak 2, dT peak 1, and dT peak 3; UV thermal melting curves; CD overlays of SMI; ${ }^{19} \mathrm{~F}$ NMR simulation; SPR sensorgrams of FP models and scrubber fitting of dissociation curves; HPLC profiles of $5^{\prime}$-biotin-FAAF-modified NarI dC sequence and MALDI-TOF characterization of peak 2; UVbased thermodynamic parameters of $\mathrm{dC}$ and $\mathrm{dT}$ series; and dissociation rate constants for four TLS models (PDF)
} 


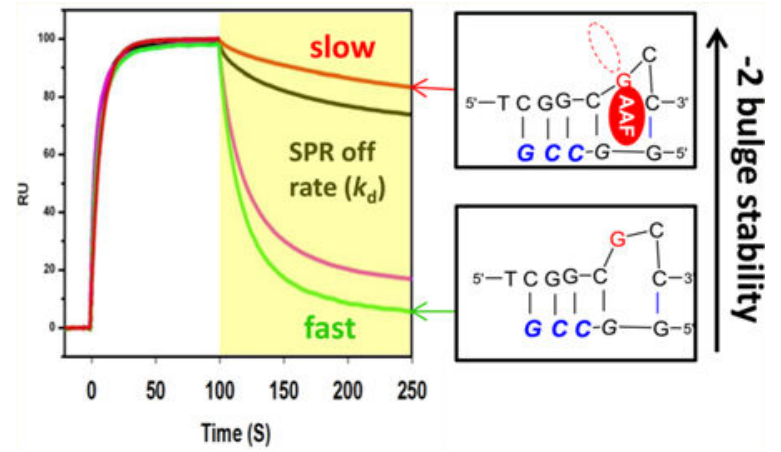

\section{INTRODUCTION}

Arylamines have been implicated in the etiology of various sporadic cancers such as bladder, lung, and breast malignancies. ${ }^{1-4}$ Upon activation in vivo, they react with cellular DNA to produce bulky DNA lesions. $N$-(2-Deoxyguanosin-8-yl)-2-aminofluorene (AF) and $N$ acetyl-(2-deoxyguanosin-8-yl)-2-aminofluorene (AAF) are the two most extensively studied arylamine-DNA lesions (Figure 1a). ${ }^{5,6}$ Despite their structural resemblance, these lesions produce different conformational characteristics. Although AF and AAF exist in a mixture of syn-stacked (S) and anti-major groove (B)-type conformations, AAF additionally adopts a stable minor groove wedge (W) conformation (Figure 1b). ${ }^{7-9}$ This arylamine-induced $\mathrm{S} / \mathrm{B} / \mathrm{W}$-conformational heterogeneity and its sequence dependence may have important implications for the mutational and repair outcomes of these lesions. ${ }^{8,10-14} \mathrm{AF}$ can be nonmutagenic by correctly base pairing with an incoming $\mathrm{dC},{ }^{15}$ whereas the bulky AAF blocks the replication process ${ }^{16}$ and requires recruitment of lesion bypass polymerases for translesion synthesis (TLS). ${ }^{17,18}$ In Escherichia coli, the TLS of AF produces point and frameshift mutations, whereas bypass of the AAF lesion is frequently accompanied by a frameshift mutation. ${ }^{19} \mathrm{AF}$ and $\mathrm{AAF}$ lesions produce primarily $\mathrm{G}$ to $\mathrm{T}$ point mutations in mammalian cells. ${ }^{19-22}$

Frameshift mutagenesis usually encompasses the gain or loss of one or more base pairs, which alters the original DNA sequence, resulting in grossly altered genetic outcomes. ${ }^{23}$ AAF-induced frameshifts usually involve slippage of base(s) in certain G:C alternating sequences. The most well-known of these frameshifts is the Nart mutational hotspot $\left(5^{\prime}\right.$ $\mathrm{CCG}_{1} \mathrm{G}_{2} \mathrm{CG}_{3} \mathrm{CX}-3^{\prime}$ ) in the E. coli plasmid pBR322. ${ }^{16,24,25}$ Studies in E. coli ${ }^{24}$ and human cells ${ }^{26}$ revealed that an $\mathrm{AAF}$ modification at $\mathrm{G}_{3}$ of the sequence increases the -2 deletion mutation frequency up to $10^{7}$-fold compared to that of the unmodified control, even though each $\mathrm{G}$ shows a similar chemical reactivity. In addition, the propensity for these mutations is greatly modulated by the nature of the nucleotide in the $X$ position $(\mathrm{C} \sim \mathrm{A}>\mathrm{G} \gg \mathrm{T}) .{ }^{27-29}$ The -2 GC deletion mutations arise from the extrusion of $A A F-G_{3}$ with the flanking $C$ into -2 base misalignment through the so-called "Streisinger" slippage mutagenic intermediate (SMl). ${ }^{28,30,31}$ This slippage is not attainable with AAF at $\mathrm{G}_{1}$ or $\mathrm{G}_{2}$ due to a lack of the required repetitive GC dinucleotide. Similarly, in monotonous runs of $\mathrm{G}$, the extrusion of AAF- $\mathrm{G}_{3}$ into a -1 base SMI during replication produces a -1 deletion mutation. ${ }^{32} \mathrm{We}$ reported that Nart-based $-1,-2$, and -3 deletion SMIs exist in a mixture of "lesion- 
exposed" conformationally flexible B-type (B-SMI) and "lesion inserted" stacked S (S-SMI) conformers. ${ }^{33}$ The results showed that the S-SMI conformation was thermodynamically stable (more stable than the B-SMI conformer), and thus, the thermodynamic stability was in the order of -1 deletion $>-2$ deletion $>-3$ deletion duplexes.

The nature of polymerases contributes to the efficiency of frameshift mutations. In E. coli, AAF in the Narl sequence prompts a specific SMI structure upstream of the active site of the Klenow fragment that allows synthesis past the lesion to occur. The study also showed a very different template-primer structure in non-NarI sequences. ${ }^{34}$ Whereas polymerase II is responsible for a -2 deletion during the TLS of AAF-G 3 in the Nar1 sequence, polymerase $\mathrm{V}$ leads to an error-free bypass in E. coli. ${ }^{28}$ Crystal structures of T7 DNA polymerase reveal that the AAF lies behind the O-helix and is stuck in the hydrophobic pocket of the finger domain, allowing the tight active site of the polymerase to adopt an open conformation. This conformational anomaly results in strong blockage, triggering a slippage that leads to various frameshifts during TLS. ${ }^{35}$ Bulky arylamine lesions exhibit multiple conformations in the spacious active sites of bypass polymerases, which may account for their complex mutational outcomes including frameshift mutations. ${ }^{36-40}$ Studies have shown that a frameshift is triggered by the unstable molecular association of the AAF-modified dG with the correct incoming nucleotide $\mathrm{dC} .{ }^{18,38,41}$ This event likely promotes the lesion-containing $\mathrm{dG}$ (alone or in sync with neighboring bases) to slip and form misaligned bulge structures.

The main objective of the present study was to investigate the detailed mechanisms of AAFinduced frameshift mutagenesis. Specifically, we sought conformational and structural insights into the propensity for the formation of -2 SMI, a critical bulge structure responsible for the -2 deletion mutation. We conducted a series of polymerase free solution experiments of Nart sequence-based 16-mer DNA templates during TLS: [ $\left(5^{\prime}-\right.$ $\mathrm{CTCTCG}_{1} \mathrm{G}_{2} \mathrm{CG}_{3}{ }^{*} \mathrm{C} X$ ATCAC-3 ${ }^{\prime}$ ); $\mathrm{G}_{3} *=$ FAAF (fluorinated AAF, Figure 1a); $X=\mathrm{C}$ or T for $\mathrm{dC}$ and dT series; Figure 2]. We examined their conformational, thermodynamic, and duplex formation properties during primer elongation by dynamic ${ }^{19} \mathrm{~F} \mathrm{NMR} /$ induced $\mathrm{CD}$, UV-melting/differential scanning calorimetry (DSC), and surface plasmon resonance (SPR), respectively. The conformational nature of the -2 SMI TLS duplexes was compared to that of the corresponding nonslipped fully paired (FP) duplexes (Figure 2). In addition, we investigated the contribution of the identity of the $3^{\prime}$-next flanking base $X$ (dC or dT series) to the stability of AAF- $\mathrm{G}_{3}$ and its propensity to undergo slippage to form -2 deletion structures during TLS.

\section{MATERIALS AND METHODS}

\section{Caution: Aminofluorene derivatives are animal carcinogens; therefore, caution is required when handling.}

Oligodeoxynucleotides (oligo, 1-10 $\mu \mathrm{mol}$ scale) in desalted form were purchased from Eurofins MWG Operon (Huntsville, AL, USA) and purified by using reverse phase HPLC. The HPLC system consisted of a Hitachi (Schaumberg, IL, USA) EZChrom Elite HPLC unit with an L2450 diode array detector and a Phenomenex (Torrabnce, CA, USA) Clarity C18 column $(150 \times 10 \mathrm{~mm}, 5.0 \mu \mathrm{m})$. All HPLC solvents were purchased from Fisher Inc. (Pittsburgh, PA, USA). 


\section{Preparation of FAAF modified DNA.}

FAAF modification of 16-mer NarI templates $\left(5^{\prime}-\mathrm{CTCTCG}_{1} \mathrm{CG}_{2} \mathrm{CX}\right.$ XTCAC-3 ${ }^{\prime}$; $\mathrm{G}^{*}=$ FAAF; $X=\mathrm{C}$ or T; Figure 2) was performed by the procedures described previously. ${ }^{7,42}$ Briefly, 1-3 mg of $N$-acetoxy- $N$-2-acetylamino-7-fluorofluorene dissolved in absolute ethanol was added to $3 \mathrm{~mL}$ of sodium citrate buffer ( $10 \mathrm{mM}$, pH 6.0) containing approximately $0.1-0.2 \mu \mathrm{mol}$ of unmodified oligo, and the solution was placed in a $37{ }^{\circ} \mathrm{C}$ water bath shaker for $5 \mathrm{~min}$. The reaction mixture was partitioned with diethyl ether to remove unreacted carcinogens. The aqueous layer was filtered through a $0.2 \mu \mathrm{m}$ membrane filter and injected to a reverse phase HPLC which consisted of 3-9\% acetonitrile for $5 \mathrm{~min}$ followed by $9-30 \%$ acetonitrile for $20 \mathrm{~min}$ in ammonium acetate buffer (100 mM, pH 7.0) with a flow rate of $2.0 \mathrm{~mL} / \mathrm{min}$ (see Figure 3 for a representative HPLC profile).

\section{Matrix-Assisted Laser Desorption Ionization-Time of Flight (MALDI-TOF) Mass Spectrometry.}

All mass spectra were obtained using a Shimadzu Axima Performance MALDI-TOF mass spectrometer (Columbia, MD, USA), according to the published procedures. ${ }^{33}$ Briefly, $1 \mu \mathrm{L}$ of analyte (control and digest samples) and a matrix solution (1:1 ratio of 3-hydroxypicolinic acid and diammonium hydrogen citrate) were mixed to produce a spotting solution. A $1 \mu \mathrm{L}$ sample of the digest solution was removed at regular time intervals until the digestion rate was significantly reduced, and the reaction was quenched by mixing the aliquot with $1 \mu \mathrm{L}$ of the matrix solution. The sample was spotted on the MALDI plate and dried for immediate analysis. All MALDI-MS spectra were obtained in a positive ion reflectron mode.

\section{UV Thermal-Melting Experiments.}

UV melting data were collected on a Cary100 Bio UV/vis spectrophotometer (Santa Clara, CA, USA) equipped with a $6 \times 6$ multicell chamber with $1.0 \mathrm{~cm}$ path length and a built-in Peltier temperature controller. Samples with a total concentration in the range of $0.5-10 \mu \mathrm{M}$ were prepared in solutions containing $0.2 \mathrm{M} \mathrm{NaCl}, 10 \mathrm{mM}$ sodium phosphate, and $0.2 \mathrm{mM}$ EDTA at $\mathrm{pH}$ 7.0. A typical melting experiment consisted of forward/reverse scans and was repeated five times. Thermodynamic parameters were calculated using the program MELTWIN version 3.5, as described previously. ${ }^{43}$

\section{Differential Scanning Calorimetry (DSC).}

All calorimetric samples were measured using Nano-DSC from TA Instrument (Lindon, UT, USA). One hundred micromolar solutions containing an unmodified or $\mathrm{G}_{3}$-FAAF modified template with various primers were prepared by dissolving in a $\mathrm{pH} 7.0$ buffer containing 20 $\mathrm{mM}$ sodium phosphate and $0.1 \mathrm{M} \mathrm{NaCl}$ and degassed at least 10 min under vacuum. The samples were scanned against the blank buffer from 15 to $85^{\circ} \mathrm{C}$ at a rate of $0.75^{\circ} \mathrm{C} / \mathrm{min}$; at least five repetitions including forward/reverse reactions were measured. Raw data were collected in the form of microwatts vs temperature. A buffer vs buffer scan was provided as a blank to be subtracted from the sample scan and normalized for heating rate. The 
thermodynamic parameters $(\Delta H, \Delta G$, and $\Delta S)$ were determined according to reported procedures. ${ }^{44}$

\section{Experiments.}

CD spectra were obtained on a Jasco J-810 spectropolarimeter (Easton, MD, USA) equipped with a Peltier temperature controller. Modified templates $(10 \mu \mathrm{M})$ were annealed with an equimolar amount of primer in $400 \mu \mathrm{L}$ of a buffer which contained $0.2 \mathrm{M} \mathrm{NaCl}, 10 \mathrm{mM}$ sodium phosphate, and $0.2 \mathrm{mM}$ EDTA ( $\mathrm{pH} 7.0$ ). The samples were incubated at $85^{\circ} \mathrm{C}$ for 5 min and cooled to room temperature to ensure duplex formation. The $\mathrm{CD}$ was scanned from 200 to $400 \mathrm{~nm}$ at a rate of $50 \mathrm{~nm} / \mathrm{min}$, and spectra were acquired 10 times and were smoothed with 25-point adaptive algorithms provided by Jasco.

\section{Dynamic ${ }^{19}$ F-NMR Spectra.}

Approximately $100 \mu \mathrm{M} \mathrm{G}_{3}$-FAAF modified 16-mer template were annealed with an equimolar amount of respective primers to produce appropriate TLS duplexes (Figure 2).

The samples were lyophilized and dissolved in $250 \mu \mathrm{L}$ of NMR buffer $\left(10 \% \mathrm{D}_{2} \mathrm{O} / 90 \% \mathrm{H}_{2} \mathrm{O}\right.$, pH 7.0 containing $100 \mathrm{mM} \mathrm{NaCl}, 10 \mathrm{mM}$ sodium phosphate, and $100 \mu \mathrm{M}$ EDTA) and filtered into a Shigemi tube through a $0.2 \mu \mathrm{m}$ membrane filter. All ${ }^{1} \mathrm{H}$ and ${ }^{19} \mathrm{~F}$ NMR results were obtained using a Varian NMR spectrometer with a HFC probe operating at 500.0 and $476.5 \mathrm{MHz}$, respectively, following the reported acquisition parameters. ${ }^{45-47}$ Imino proton spectra were recorded at 5 to $60{ }^{\circ} \mathrm{C}$ using a phase sensitive jump return sequence and referenced to DSS. ${ }^{19} \mathrm{~F}$ NMR spectra were acquired in the $5-70{ }^{\circ} \mathrm{C}$ temperature range with an increment of 5 or $10{ }^{\circ} \mathrm{C}$ in the ${ }^{1} \mathrm{H}$-decoupled mode and referenced to $\mathrm{C}_{6} \mathrm{~F}_{6}$ in $\mathrm{C}_{6} \mathrm{D}_{6}$ at $-164.9 \mathrm{ppm}$. The conformer population percentage was simulated by using computer line shape simulations which were performed as described previously using WINDNMR-Pro (version 7.1.6; J. Chem. Edu. Software Series; Reich, H. J., University of Wisconsin, Madison, WI, USA). ${ }^{42,47}$

\section{Surface Plasmon Resonance (SPR).}

A series of SPR sensograms were obtained in a polymerase-free environment using a Biacore T200 instrument (GE Healthcare, Pittsburgh, USA). Sixteen-mer biotinylated DNA template strands ( $5^{\prime}$-biotin-CTCTCGGCGC XATCAC- $3^{\prime}, \mathrm{X}=\mathrm{C}$ or $\mathrm{T}$ ) have the same sequence contexts as those utilized in the NMR studies above (Figure 2). The biotinylated oligonucleotides were modified with FAAF by using the usual biomimetic procedures and purified by HPLC. ${ }^{48,49}$ The HPLC gradient condition for biotin FAAF-modified oligos was different from that of the nonbiotin labeled oligos described above because of the hydrophobic biotin residue: $\mathrm{dC}$ series, $5-15 \%$ acetonitrile with $100 \mathrm{mM}$ of ammonium acetate buffer for $10 \mathrm{~min}$ followed by $15-38 \%$ acetonitrile for $5 \mathrm{~min}$ and $38 \%-5 \%$ for $5 \mathrm{~min}$; dT series, $8 \%-15 \%$ acetonitrile for $20 \mathrm{~min}$ followed by $15-38 \%$ acetonitrile for $10 \mathrm{~min}$ and $38-8 \%$ for $5 \mathrm{~min}$ in ammonium acetate buffer at a flow rate of $2.0 \mathrm{~mL} / \mathrm{min}$. The biotin labeled adducts were characterized by MALDI-TOF-MS using $3^{\prime}$ enzyme digestion since $5^{\prime}$ of DNA was labeled by biotin, the $5^{\prime}$ exonuclease enzyme did not apply in this case. 
A carboxymethylated CM 5 chip was activated by an amine coupling kit according to published procedures. ${ }^{49}$ Generally, the EDC/NHS mixture was injected over the chip for 7 min and followed by coating streptavidin (SA, $50 \mathrm{ug} / \mathrm{mL}$ dissolved in sodium acetate buffer, pH 4.5) on flow cells 2 and 4, while flow cell 1 and 3 were left blank. One molar ethanolamine was injected over the surface to block the unreacted esters. Five pulses of 50 $\mathrm{mM} \mathrm{NaOH}$ were injected over the chip to remove the unbound SA, and running buffer stabilized the surface for 20-30 min before DNA coating. Flow cells 2 and 4 were coated around $200 \mathrm{RU}$ of unmodified DNA and FAAF-modified under the manual control mode. Different lengths of primer sequences were prepared in HBS- $\mathrm{P}^{+}$buffer $(10 \mathrm{mM}$ Hepes, 150 $\mathrm{mM} \mathrm{NaCl}$, and $0.05 \%$ surfactant $\mathrm{P} 20$ at $\mathrm{pH} 7.4$ ) and injected over the chip surface at $25^{\circ} \mathrm{C}$ with $100 \mathrm{~s}$ contact time and $360 \mathrm{~s}$ dissociation time at a $15 \mu \mathrm{L} / \mathrm{min}$ flow rate. Each elongation required different concentrations of complementary strands to achieve steadystate associations: (n-1) $25 \mathrm{nM}$, (n) $50 \mathrm{nM},(\mathrm{n}+1) 75 \mathrm{nM},(\mathrm{n}+2) 100 \mathrm{nM}$, and $(\mathrm{n}+3)(\mathrm{n}+6)(\mathrm{n}$ +8) $150 \mathrm{nM}$. After reaching a steady state, primers were washed off by a running buffer, and the system was regenerated by $\mathrm{NaOH}$ addition $(50 \mathrm{nM}, 30 \mathrm{~s})$. Dissociation rate constants $\left(k_{\mathrm{d}}\right)$ were determined and analyzed using Scrubber software (version 2.0, Myszka and collaborators, BioLogic Software) in $k_{\mathrm{d}}$-alone fitting mode. The goodness of the fit was determined from the residual standard deviation.

\section{RESULTS}

\section{Experimental DNA Sequences.}

We employed two DNA templates, in which FAAF is positioned at $\mathrm{G}_{3}$ of a 16-mer Nart sequence (5'-CT $\underline{{ }^{\prime} T C G_{1}} \mathrm{G}_{2} \underline{C G}_{3}{ }^{*} \mathrm{CX}$ ATCAC- $3^{\prime} ; \mathrm{X}=\mathrm{C}$ or $\mathrm{T}$ for $\mathrm{dC}$ and $\mathrm{dT}$ series, respectively) (Figure 2). The fluorine containing FAAF was utilized to measure the dynamic ${ }^{19} \mathrm{~F}$ NMR. ${ }^{11}$ The underlined 12-mer portion of the above sequence is identical to that used in our previous work on 12/10-mer -2 deletion duplexes, in which we utilized FAF as a model. ${ }^{45}$ Initially, we wanted to use the same 12-mer template for consistency but found it to be too short for producing thermally stable $\mathrm{n}-1$ (12/5-mer) or $\mathrm{n}$ (12/6-mer) duplexes. Therefore, we added two bases on both sides (CT and $\mathrm{AC}$ on the $5^{\prime}$ and $3^{\prime}$ side, respectively) to a longer template (e.g., 16-mer). As expected, the modified 16-mer produced stable TLS models while maintaining the same inner core sequence.

Insertion of the correct cytosine opposite the FAAF-modified $\mathrm{G}_{3} *$ in the Nart sequence can produce either a $\mathrm{G} 3 * \mathrm{CorCG}^{*} *-2$ bulge-out structure, depending on the nature of Streisinger slippage (Figure 2b). ${ }^{23}$ Using ${ }^{1} \mathrm{H}$ NMR to study an AAF-modified Nart-based SMI 11/9-mer duplex, $\left(5^{\prime}\right.$-ACCG1G2C $\left.{ }_{3}{ }^{* C C A C A}-3^{\prime}\right)-\left(5^{\prime}\right.$-TGTG--GCCGGT-3'), Milhe et al. ${ }^{50,51}$ revealed that $\sim 80 \%$ of the modified G3* were in syn-conformation with the G3*C-2 bulge-out S-SMI structure (underlined), in which the bulky lesion was inserted into the bulge. A ${ }^{1} \mathrm{H}$ NMR study by Mao et al. ${ }^{9}$ involving an AF-modified Nart-based -2 SMI 12/10-mer duplex $\left[\left(5^{\prime}-\mathrm{CTCG}_{1} \mathrm{G}_{2} \mathrm{CG}_{3}{ }^{*}{ }_{-}\right.\right.$CCATC- $\left.3^{\prime}\right)\left(5^{\prime}\right.$-GATGG--CCGAG-3 $\left.\left.{ }^{\prime}\right)\right]$ showed an exclusive S-SMI conformation with the $\mathrm{CG}_{3}$ * bulge-out structure (underlined). We showed previously that this AF-modified 12/10-mer -2 bulge duplex adopts a mixture of syn-and anti-glycosidic conformers. ${ }^{45}$ From the mutation outcomes, one cannot distinguish between the $\mathrm{CG}_{3} *$ and $\mathrm{G}_{3}{ }^{*} \mathrm{C}$ SMI possibilities, as either could lead to a -2 deletion from the NarI 
sequence $\mathrm{CG}_{1} \mathrm{G}_{2} \mathrm{CG}_{3} \mathrm{CC}$ to $\mathrm{CG}_{1} \mathrm{G}_{2} \mathrm{CC}$. $^{9,28}$ However, these results indicate the importance of lesion structure in defining the nature of the -2 SMI bulge structure. The AAF-induced -2 mutation on the $\mathrm{Nar}$ sequence by the bypass polymerase pol $\eta$ follows Milhe's $\mathrm{G}_{3} * \mathrm{C}$ bulgeout model mentioned above. ${ }^{39,41}$ Additional experimental data ${ }^{27,28}$ and theoretical calculations ${ }^{31}$ confirmed the favorability of AAF to adopt a $\mathrm{G}_{3} * \mathrm{C}$ rather than a $\mathrm{CG}_{3} *$ bulge structure. On the basis of these findings, we selected the $\mathrm{G}_{3} * \mathrm{C}$ bulge as a favorable -2 SMI for AAF (Figure 2b). Accordingly, we constructed eight model TLS systems: four fully paired (FP) and four $-2 \mathrm{G}^{*} \mathrm{C}$ bulge $\mathrm{SMI}$, for each of the $\mathrm{dC}$ and $\mathrm{dT}$ series (Figure 2). In the FP model (Figure 2a), the 16-mer template (unmodified and FAAF-modified) was paired with appropriate primers to form ss/ds duplexes at n-1 (16/7-mer), n (16/8-mer), n+1 (16/9 mer), $n+2$ (16/10-mer), $n+3$ (16/11-mer), and a fully paired duplex at $n+8$ (16/16-mer). In the SMI model (Figure $2 \mathrm{~b}$ ), primers were added judiciously to create $-2 \mathrm{G}_{3} * \mathrm{C}$ bulge structures, at n-1 (16/7-mer), n (16/8-mer), n+1 (16/9-mer), n+2 (16/10-mer), n+3 (16/11mer), and n+6 (16/14-mer).

Modified templates $\left(5^{\prime}-\mathrm{CTCTCG}_{1} \mathrm{G}_{2} \mathrm{CG}_{3} * \mathrm{C} X \mathrm{ATCAC}-3^{\prime}, X=\mathrm{C}\right.$ or $\left.\mathrm{T}\right)$ were synthesized by treating an unmodified 16-mer with activated FAAF, according to published procedures. 7,42,45 A typical HPLC profile (Figure 3) showed all seven possible FAAF-modified dG adducts in less than $20 \mathrm{~min}$ : three mono (11-14min)-, three di (16-19 min)-, and one tri (20 min)-adduct. This result is significant improvement over previous HPLC conditions, in which all modified peaks were collected in over 90 min of gradient time (Figure S1b; ${ }^{13}$ see Materials and Methods). AAF multiplicity was determined based on their UV shoulder intensities in the $300-325 \mathrm{~nm}$ range (Figure $3 \mathrm{~b}$ ). ${ }^{12}$

\section{Mass Spectral Characterization of FAAF-Modified 16-Mer Templates.}

FAAF-modified monoadducts were characterized by exonuclease enzyme digestion followed by MALDI-TOF mass spectrometry, according to published procedures. ${ }^{14,33,52}$

$5^{\prime}-$ CTCTCG $_{1} \mathrm{G}_{2} \mathrm{CG}_{3}[\mathrm{FAAF}] \mathrm{CCATCAC-3^{ \prime }}$ (dC Series).-Figure $\mathrm{S} 2$ shows the MALDI-TOF MS spectra of the $3^{\prime}-5^{\prime}$ snake venom phosphodiesterase (SVP) and $5^{\prime}-3^{\prime}$ bovine spleen phosphodiesterase (BSP) exonuclease digestions of HPLC peak 2 (Figure 3a) at different time points. The $5^{\prime}-3^{\prime}$ exonuclease reaction was significantly slower than the $3^{\prime}$ $-5^{\prime}$-exonuclease counterpart. Briefly, the $\mathrm{m} / \mathrm{z}$ of 5017 at $0 \mathrm{~s}$ represents the control mass to charge ratio of the modified template (e.g., before digestion). Within $30 \mathrm{~s}$ of $3^{\prime}-5^{\prime}$ exonuclease digestion (Figure S2a), the control molecular ion $\mathrm{m} / \mathrm{z}$ of 5017 was replaced with three lower masses, at $m / Z=3508,3218$, and 2929, corresponding to the 11-, 10-, and 9-mer fragments with two, one, and no extra base on the $3^{\prime}$-flanking side of the lesion site, respectively (see inset). The 9 -mer peak at $m / z=2929$ (theoretical 2928.67) was the only detectable mass at $120 \mathrm{~s}$. The $5^{\prime}-3^{\prime}$ exonuclease digestion (Figure $\mathrm{S} 2 \mathrm{~b}$ ) produced $\mathrm{m} / \mathrm{z}=$ 2883 , which matches the value for the fragment that was cleaved one base before the lesion. An additional peak $\mathrm{m} / \mathrm{z}$ of 2594 at $30 \mathrm{~min}$ of digestion corresponded to the 8-mer containing FAAF at $\mathrm{G}_{3}$. Taken together, these results confirm peak 2 as the $\mathrm{G}_{3}$-FAAF-modified 16-mer $\mathrm{dC}$ series $(N=\mathrm{dC})$. HPLC peaks 1 and 3 in Figure 2a were similarly characterized as $\mathrm{G}_{1^{-}}$ (Figure $\mathrm{S} 3$ ) and $\mathrm{G}_{2}$-modified (Figure $\mathrm{S} 4$ ), respectively. 
$5^{\prime}$-CTCTCG ${ }_{1} \mathrm{G}_{2} \mathrm{CG}_{3}[\mathrm{FAAF}] \mathrm{CTATCAC-3^{ \prime }}$ (dT Series).-Figure $\mathrm{S} 5$ shows the MALDITOF MS spectra of HPLC peak 2 with $3^{\prime}-5^{\prime}$ and $5^{\prime}-3^{\prime}$ (Figure S5) exonuclease digestions, with the control molecular ion $\mathrm{m} / \mathrm{z}$ of 5031 at $0 \mathrm{~s}$. The $\mathrm{m} / \mathrm{z}$ peaks of 3218 and 2928 for the $120-180 \mathrm{~s}$ of $3^{\prime}-5^{\prime}$ - exonuclease digestion (Figure S5a) corresponded to the 10- and 9-mer fragments with one and no extra base at the $3^{\prime}$ side of the lesion site, respectively (in set). The fragment with $\mathrm{m} / \mathrm{z}=2896$ after $60 \mathrm{~min}$ of $5^{\prime}-3^{\prime}$ exonuclease digestion (Figure S5b) corresponded to a signal with one extra base at the $5^{\prime}$ side of the lesion (inset). These results confirm peak 2 as the $\mathrm{G}_{3}$-modified 16-mer dT series. Similarly, HPLC peaks 1 and 3 in the dT series contained FAAF at $\mathrm{G}_{1^{-}}$(Figure $\mathrm{S} 6$ ) and $\mathrm{G}_{2}$-modified (Figure S7), respectively.

\section{Thermodynamic Studies.}

UV Melting Curves.-All of the TLS model duplexes (Figure 2) were prepared in the concentration of $0.5-10 \mu \mathrm{M}$ and measured UV thermal melting profiles which showed mostly monophasic and sigmoidal curves (Figure $\mathrm{S} 8)$. The observed correlation $\left(R^{2}>0.9\right)$ between $\ln C_{\mathrm{t}}$ and $T_{\mathrm{m}}{ }^{-1}$ confirmed that the duplexes showed typical helix-coil transitions. ${ }^{8,43}$ Figure 4 shows the plots of duplex melting $\left(T_{\mathrm{m}}\right)$ as a function of primer elongation for the FP and SMI-TLS systems. The FP-TLS models serve as structural controls for the SMI systems. Results of the FAAF-modified systems (red, empty circles) were compared to results from the corresponding unmodified controls (blue, filled circles). Tables S1 and S2 summarize the thermal and thermodynamic parameters calculated from the UV melting curves.

As shown in Figure 4a, the lesion effect in the FP/dC and SMI/dC systems was minimal near the lesion site $(\mathrm{n}-1$ to $\mathrm{n}+1)$ but exhibited significant differences in the later stages of TLS ( $\mathrm{n}$ +2 to full). In SMI/dC, FAAF modification increased the thermal stability in the $\mathrm{n}+1$ to $\mathrm{n}+6$ stage of TLS, with $\Delta T_{\mathrm{m}}$ increasing from 3.2 to $13.1^{\circ} \mathrm{C}$, respectively. In contrast, the FP/dC exhibited consistently lower stability, with $\Delta T_{\mathrm{m}}$ of -6.2 to $-15.6{ }^{\circ} \mathrm{C}$ in the $\mathrm{n}+1$ to $\mathrm{n}+6$ stages of TLS (Table S1). A minimal lesion effect was predicted in the $n-1$ to $n+1$ position because of uncertainty in the SMI structure up to this point. The dramatic stabilization of the FAAFmodified model compared to the control SMI model (SMI/dC, Figure 4a) in the $n+2$ to $n+6$ range was due to the formation of the -2 bulge structure, in which the hydrophobic FAAF lesion was stacked in the solvent-protected environment. By contrast, the negative thermosdynamic effect in the FP/dC system could be due to the S/B/W-conformational heterogeneity (see ${ }^{19} \mathrm{~F}$ NMR below). A similar $T_{\mathrm{m}}$ pattern was observed in the dT series (Figure $4 \mathrm{~b}$ ). The FAAF-FP/dT system was less stable than the control FP/dT system, with a $\Delta T_{\mathrm{m}}$ of -19.4 to $-9.6{ }^{\circ} \mathrm{C}$. In the SMI/dT model, substantial stabilization was observed from $\mathrm{n}+2$ to $\mathrm{n}+6$, with $\Delta T_{\mathrm{m}}$ of $\sim 10.5^{\circ} \mathrm{C}$ (Table $\mathrm{S} 2$ ).

DSC-Based Microcalorimetry.-We performed DSC experiments for the SMI models (SMI vs FAAF-SMI) only to determine thermodynamic parameters. The DSC thermograms are shown as overlays in Figure 5, with the maximum point corresponding to $T_{\mathrm{m}}$ and areas under $T_{\mathrm{m}}$ representing the enthalpy changes $(\Delta H)$. Unlike the UV melting curves, the DSC results are independent of concentration, thus yielding reliable thermodynamic parameters. Table 1 summarizes the DSC results. ${ }^{53}$ 
Control SMI/dC, and SMI/dT.-Figure 5a shows the DSC thermograms for the control $\mathrm{SMI} / \mathrm{dC}$. The 16/7-mer duplex at $\mathrm{n}-1$ (cyan) showed a broad curve, with $T_{\mathrm{m}}=35.1{ }^{\circ} \mathrm{C}$ and $\Delta H=-45.0 \mathrm{kcal} / \mathrm{mol}$ (Table 1). The curve became more Lorentzian with one additional base (n), with $T_{\mathrm{m}}=48.5^{\circ} \mathrm{C}$ and $\Delta H=-48.5 \mathrm{kcal} / \mathrm{mol}$. The $T_{\mathrm{m}}$ and $\Delta H$ values were mostly constant until $\mathrm{n}+3$ but increased significantly at $\mathrm{n}+6\left(T_{\mathrm{m}}=57.3^{\circ} \mathrm{C}, \Delta H=-120.9 \mathrm{kcal} / \mathrm{mol}\right)$. This kind of thermodynamic DSC clustering in the $n \sim n+3$ TLS duplexes is not expected for standard primer DNA elongation, clearly indicating the formation of a -2 SMI bulge structure. The dT series SMI/dT (Figure 5c) showed a very similar DSC profile, except that the $\Delta H$ values were smaller throughout TLS.

FAAF-SMI/dC.-Figure 5b shows the DSC profiles for FAAF-modified SMI in the dC series. The $T_{\mathrm{m}}$ and $\Delta H$ values increased progressively with increasing primer elongation from $n-1$ to $n+3$. In contrast, the $n$ to $n+3$ curves of the unmodified controls were clustered around $48{ }^{\circ} \mathrm{C}$ (Figure 5a). This pattern resembles that of fully paired unmodified TLS duplexes, which exhibit incremental $T_{\mathrm{m}} / \Delta H$ increases with primer elongation. ${ }^{53}$ As in the UV melting curves, these results support the unique stabilizing effect of FAAF through the TLS process.

FAAF-SMI/dT.-A similar DSC profile was observed for the dT series (Figure 5d). As in the unmodified controls (Figure 5c), the dT series exhibited consistently smaller $T_{\mathrm{m}}$ and $\Delta H$ values. The $T_{\mathrm{m}}$ of the $\mathrm{n}-1$ duplex was smaller than that of the $\mathrm{dC}$ series $\left(32.3^{\circ} \mathrm{C}\right.$ vs $41.9^{\circ} \mathrm{C}$; Table 1). The increase in $\Delta H$ was not as incremental as that of $T_{\mathrm{m}}$, similar to the $\mathrm{dC}$ series above. This finding can be attributed to the presence of a weak T:A base pair, instead of the more stable C:G base pair, at the $3^{\prime}$-next flanking base $X\left(5^{\prime}-\mathrm{CGGCG}^{*} \mathrm{C} X-3^{\prime}\right)$. Taken together, these results indicate that FAAF-modified TLS systems are generally more stable than the unmodified control systems.

\section{Conformational Probing of TLS Duplexes at Single/Double Strand Junctions.}

Induced CD (ICD) is a sensitive technique for probing arylamine-induced S/B/Wconformational heterogeneity ${ }^{13,33,45}$ and allows measurements of the global conformation at early TLS stages. Figure 6 shows the CD overlays of modified SMI duplexes in the $\mathrm{dC}$ and dT series during the early stages of TLS (i.e., from $n-1 \rightarrow n \rightarrow n+1$ ). The gradual increase of ellipticity in the $\mathrm{dC}$ series (Figure 6a) at $270 \mathrm{~nm}$ indicates a lesion-induced strengthening of base stacking. This trend was not observed for the dT series (Figure 6b). Figure S9 shows the CD spectra of the FAAF-SMI duplexes (red) overlaid with those of the unmodified controls (blue) from $\mathrm{n}-1$ to $\mathrm{n}+6$ in the $\mathrm{dC}$ and $\mathrm{dT}$ series. In all cases, the modified duplexes exhibited blue shifts relative to the controls, with greater effects being evident for the $\mathrm{dC}$ compared to the dT series (dC series, $6 \mathrm{~nm}$ at $\mathrm{n}-1$ to $\mathrm{n}, 5 \mathrm{~nm}$ at $\mathrm{n}+1$ to $\mathrm{n}+3,7 \mathrm{~nm}$ at $\mathrm{n}+6$; dT series, $4 \mathrm{~nm}$ at $\mathrm{n}-1,2 \mathrm{~nm}$ at $\mathrm{n}, 3 \mathrm{~nm}$ at $\mathrm{n}+1$ to $\mathrm{n}+2,1 \mathrm{~nm}$ at $\mathrm{n}+3$ to $\mathrm{n}+6$; Figure $\mathrm{S} 9$ ). These ICD results suggest that the base stacking of the $\mathrm{dC}$ series is generally greater than that of the dT series.

\section{Conformational Heterogeneity of TLS Duplexes.}

Dynamic ${ }^{19} \mathrm{~F}-\mathrm{NMR}$ was conducted to measure conformational heterogeneity during TLS. Figures 7 and 8 show the dynamic ${ }^{19} \mathrm{~F}$ NMR spectra $\left(5-70{ }^{\circ} \mathrm{C}\right)$ of the FAAF-modified SMI 
system for the $\mathrm{dC}$ and $\mathrm{dT}$ series, respectively (see Figure $2 \mathrm{~b}$ for all SMI TLS sequences). These TLS duplexes exhibited a mixture of ${ }^{19} \mathrm{~F}$ signals, each representing a unique electronic environment. ${ }^{8,11,54}$ The $n+6$ TLS models represent 16/14-mer -2 duplexes, in which the $\mathrm{G}_{3} * \mathrm{C}$ portion is bulged out.

FAAF-SMI/dC.-In all TLS stages (Figure 7), the ${ }^{19} \mathrm{~F}$ signals coalesced into a sharp single peak above $60{ }^{\circ} \mathrm{C}$ around $-115 \mathrm{ppm}$. This result indicates fast averaging of the FAAFmodified single-strand template. Conformational heterogeneity was apparent at $\mathrm{n}-1$, where the $3^{\prime}$ end of the primer was located at one base before the lesion site (see Figure $2 b$ ). The heterogeneity became more complex as the SMI bulge formation was about to occur at $\mathrm{n}$ and $\mathrm{n}+1$. The SMI structure was matured at $\mathrm{n}+3$ and completed at $\mathrm{n}+6$.

We assigned ${ }^{19} \mathrm{~F}$ signals based on our previous observation that the $\mathrm{B}, \mathrm{S}$, and $\mathrm{W}$ conformations of a fully paired FAAF-modified duplex appear at -115.0 to $-115.5 \mathrm{ppm}$, -115.5 to $-117.0 \mathrm{ppm}$, and -116.5 to $-118.0 \mathrm{ppm}$, respectively. ${ }^{7,11,13,14,45}$ The downfield $-115 \mathrm{ppm}$ signal at the coalescence temperature can be attributed to the denatured single strand, in which the ${ }^{19} \mathrm{~F}$ tag is fully exposed to solvent. This signal is consistent with the Btype conformer, in which the ${ }^{19} \mathrm{~F}$ tag is fully exposed to the solvent in the major groove area. The shielded signal at $-116.3 \mathrm{ppm}$ could arise from van der Waals interactions between the ${ }^{19} \mathrm{~F}$ tag and neighboring base pairs, as is the case in the $\mathrm{S}$ or, possibly, $\mathrm{W}$ conformer. However, the -2 bulge structures did not display any of the S/B/W configurations that are typically discernible in fully paired DNA duplexes. The two ${ }^{19} \mathrm{~F}$ signals at -115.5 and $-116.4 \mathrm{ppm}$ at $25^{\circ} \mathrm{C}$ in the $\mathrm{n}+6$ duplex (e.g., complete -2 bulge structure) could be collectively assigned as "lesion-exposed" (e.g., B-SMI) or "lesion-stacked" (S-SMI) conformers (see Discussion). ${ }^{45}$ A small signal at $-114.8 \mathrm{ppm}$ (marked as \#) was observed at 5 to $10{ }^{\circ} \mathrm{C}$ and coalesced with the B-SMI signal at $20^{\circ} \mathrm{C}$. The identity of this minor conformer could not be characterized. The B- and S-SMI designations can only be made at the $n+1, n+3$, and $n+6$ TLS stages, in which two well-defined signals were obtained (Figure 7). However, the $\mathrm{n}-1$ and $\mathrm{n}$ duplexes exhibited a mixture of narrow and broad signals, probably due to the presence of conformationally flexible species between the B- and S-SMI -2 bulge structures.

FAAF-SMI/dT.-Despite the similarity in their ${ }^{19} \mathrm{~F}$ signal patterns, the dT series (Figure 8) revealed greater conformational heterogeneity at the $n-1$ and $n$ duplexes than the $\mathrm{dC}$ series. Specifically, at least four different conformations were observed in the dT series in the -113 to $-117 \mathrm{ppm}$ range at the beginning of bulge formation. This complexity largely disappeared at $\mathrm{n}+1$, presumably due to the formation of a stable $\mathrm{G}_{3} * \mathrm{C}$ bulge structure. This pattern persisted at $\mathrm{n}+3$, with one major $(-115.3 \mathrm{ppm})$ and one minor $(-116.2 \mathrm{ppm})$ signal. The pattern continued into a fully elongated -2 SMI duplex at $n+6$. These results indicate that a primer extension of three bases after the lesion site is sufficient to produce a stable -2 SMI.

As was the case for the $\mathrm{dC}$ series, the signals in the $\mathrm{n}+6$ duplex were assigned to the $\mathrm{B}$ - and S-SMI conformers. The minor upfield S-SMI signal gradually coalesced into the B-SMI signal at $55^{\circ} \mathrm{C}\left(\mathrm{n}+6\right.$, Figure 8). The merged signal broadened at $60{ }^{\circ} \mathrm{C}$ and sharpened at $70{ }^{\circ} \mathrm{C}$, owing to the denaturation of the modified FAAF template in the single-stranded form. These results are consistent with the UV melting and DSC data presented above. The $20^{\circ} \mathrm{C}$ 
spectra of the $\mathrm{n}+6$ SMI were simulated by line fittings (Figure S10). The relative ratio results showed 59\% B-SMI (-115.2 ppm) and 41\% S-SMI (-116.1 ppm) conformers in the $\mathrm{dC}$ series and $86 \%$ B-SMI (-115.1 ppm) and 14\% S-SMI (-115.9 ppm) conformers in the dT duplex.

\section{SPR Binding Affinity Measurements for TLS Duplexes.}

We performed SPR experiments in order to probe the effect of lesion-induced conformational heterogeneity in a polymerase free condition. SPR measurements were used to determine real-time association/dissociation between template and primer strands in the absence of a polymerase. The results provide the binding strength of SMI bulge structures produced during a TLS. Figure 9 shows the SPR sensorgrams for the FAAF-SMI systems in the $\mathrm{dC}$ and $\mathrm{dT}$ series, compared to those for the unmodified controls. Different colors represent different primer-template duplexes. Figure S11 shows the corresponding set of SPR sensograms for the FP system. The general experimental protocol for these "zipper" experiments in a polymerase-free solution environment was reported previously. ${ }^{14}$ Traditional binding affinity $\left(K_{\mathrm{D}}\right)$ values could not be determined because we used different primer concentrations for each primer strand. However, since all of the experimental conditions were identical, the response unit (RU) and dissociation rate $\left(k_{\mathrm{d}}\right)$ values can be used to evaluate the binding characteristics during the TLS. Dissociation curves were determined to obtain $k_{\mathrm{d}}$ values (Figure S12) for each primer elongation position, and the results are summarized in Table S3. HPLC profiles and MALDI-TOF mass spectral characterization of FAAF-modified 5' -biotin-16-mer Narl sequence templates are shown in Figures S13 and S14, respectively.

The unmodified SMI controls (Figure 9a and $\mathrm{c}$ for $\mathrm{dC}$ and $\mathrm{dT}$ series, respectively) exhibited a large gap in RU values between the $n+2$ (16/10-mer; red) and $n+3$ (16/11-mer; green) steps. This is contrasted to the fully elongated FP controls (Figure S11a, c) that showed consistent RU increases throughout TLS. These results indicate the formation of a -2 bulge structure in the SMI system. Upon FAAF modification (Figure 9b, d for dC and dT series, respectively), however, there was a gradual increment of RU values with increasing primer length with noticeable reduction in dissociation rates. These results suggest a strong lesion effect at $\mathrm{G}_{3}$ in the formation of the SMI. For example, the binding strengths of the FAAFmodified SMIs for the $\mathrm{dC}$ and $\mathrm{dT}$ series at $\mathrm{n}+1$ (16-/9-mer, pink) were increased 1.9-fold (2.67/1.39) and 3.3-fold (35.0/10.6) relative to the unmodified SMI controls, respectively. The lesion effect persisted for the $\mathrm{dC}$ and dT series at $\mathrm{n}+2$ (dC, 30-fold, 3.00/0.099; dT, 27fold, 14.8/0.559), $\mathrm{n}+3$ (dC, 8-fold, 0.311/0.041; dT, 46-fold, 8.08/0.175), and $\mathrm{n}+6$ (dC, 8 fold, 0.146/0.0188; dT, 3-fold, 0.0898/0.0279) (Table S3).

Figure 10a shows overlays of the normalized dissociation curves for the unmodified and FAAF-modified models with the FP and SMI settings in the $\mathrm{dC}$ series at various primer elongation points $(n+1$ to $n+6 / 8)$. Dissociation of ss/ds primer-template duplexes begins at $100 \mathrm{~s}$ when the primer solution is no longer flowing over the immobilized DNA constructs. Slower dissociation indicates greater thermodynamic stability of the ss/ds template/primer duplexes. The different dissociation off rates are based on the duplexes' conformational stability. In all cases, decays were slowed down with increasing primer length where longer 
primers tends to have more stability, e.g., compare $n+2$ and $n+6 / n+8$ in the $d C$ series (Figure 10a). The results also illustrate a dramatic lesion/SMI effect on the dissociation rates during TLS. The stabilizing effect of the hydrophobic FAAF on the -2 bulge structure (red) relative to the fully paired (FP) controls (black) can be observed from $n+1$ to $n+3$ in the SMI-TLS system. For example, TLS duplex stability at $n+2$ of the $\mathrm{dC}$ series (Figure 10a) is increased in the same order as slow dissociation: FAAF-SMI (red) > FP (black) > FAAF-FP (pink) > SMI (green). This is not the case for the dT series (Figure 10b), where the dissociation of FAAF-modified (red) was faster than that of the FP controls (black). These results suggest greater binding stabilization of FAAF-SMI in dC than dT.

\section{DISCUSSION}

We investigated the mechanism of bulky lesion-induced frameshift mutagenesis by examining the conformational basis of generating the -2 bulge-structure SMI, which is responsible for AAF-induced -2 deletion mutations in the Nart hotspot. Previously, we showed that fully elongated AF-modified 12/10-mer -2 bulge duplexes [ $\left(5^{\prime}\right.$ $\left.\mathrm{CTCG}_{1} \mathrm{G}_{2} \mathrm{CG}_{3} * \mathrm{C} X \mathrm{ATC}\right)$ :-( $5^{\prime}$-GAT YG--CCGAG- $\left.3^{\prime}\right)$ adopt a mixture of S- and B-SMIs, with their conformational complexity dictated by the nature of $X(\mathrm{dC}$ vs dT $) .{ }^{45}$ The current study focused on the conformational and thermodynamic details of how the AAF-modified SMIs are formed.

\section{Overall TLS.}

Figure 11 presents a cartoon model for FAAF-induced -2 frameshift mutagenesis, constructed based on the gathered spectroscopic $\left({ }^{19} \mathrm{~F}\right.$ NMR/ICD), thermodynamic (UVmelting/DSC), and affinity binding (SPR) data. The model provides the detailed conformational evolution of how -2 SMI bulges are formed during TLS ( $n-1$ to $n+6)$ based

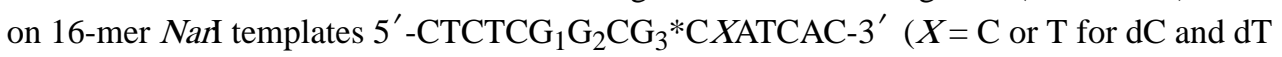
series, respectively; Figure $2 \mathrm{~b}$ ). Each step is labeled $(\mathbf{A})$ to $(\mathbf{G})$, where $(\mathbf{G})$ represents the fully elongated 16/14-mer -2 SMI TLS duplex. At $n-1$, modified $\mathrm{G}_{3}{ }^{*}$ at the ss/ds replication fork (A) exists in a mixture of flexible conformations, as evidenced by the appearance of a complex set of sharp and broad signals in the dynamic ${ }^{19} \mathrm{~F}$ NMR spectra (Figures 7 and 8). FAAF-modified $\mathrm{G}_{3} *$ pairs with the correct base $\mathrm{dC}$ at lesion site $\mathrm{n}$. The presumed $\mathrm{G}_{3} * \mathrm{C}$ pair $(\mathbf{B})$ is less conformationally and thermodynamically stable than the regular WatsonCrick-based G:C pair because the bulky FAAF-dG tends to favor a syn-glycosidic conformation. ${ }^{31,55}$ This conformational anomaly could block a replicative polymerase, prompting recruitment of a bypass DNA polymerase for TLS.

The conformationally unstable $s y n-\mathrm{G}_{3} *: \mathrm{C}$ base pair $(\mathbf{B})$ can trigger two different pathways, a one-base $\mathrm{C}$ slippage or a two-base $\mathrm{CG}$ slippage, leading to the $\mathrm{CG}^{*}(\mathbf{C})$ or $\mathrm{G}^{*} \mathrm{C}(\mathbf{D})-2 \mathrm{SMI}$ structure, respectively. Experimental ${ }^{50}$ and theoretical ${ }^{31}$ results indicate the $\mathrm{G}_{3} * \mathrm{C}-2$ bulge as the most likely scenario for the FAAF-induced TLS pathway (e.g., $\mathbf{A} \rightarrow \mathbf{B} \rightarrow \mathbf{D} \rightarrow \mathbf{E}$ $\rightarrow \mathbf{F} \rightarrow \mathbf{G}) \cdot{ }^{27,28}$ Conformational rigidity improves as the length of the primer increases, resulting in two very different -2 SMI conformers at $n+3$ and, ultimately, the fully mature conformer at $\mathrm{n}+6(\mathbf{G})$. In the B-SMI conformer, the lesion is fully exposed to solvent, 
similar to the fully paired B-type duplex conformation. ${ }^{54}$ In the S-SMI conformer, the lesion is inserted/stacked into the bulge structure and protected from solvent.

The lesion-induced conformational rigidity is progressive during TLS as illustrated in the Figure 11 inset. The B-SMI conformer (light dotted line) is likely to be more conformationally flexible than the stacked S-SMI conformer (solid dotted line) at $n+1$ (as in E). Development continues to improve the rigidity for the B- and S-SMI conformers at fully paired $n+6$ duplexes (solid dotted and solid lines, respectively). The progressive nature of bulge stability is supported by the incremental variances of the $T_{\mathrm{m}}$ and $\Delta H$ values observed by UV-melting and DSC, as well as by the SPR binding characteristics and dissociation rates during TLS.

\section{Sequence Effect.}

We observed a significant $\mathrm{S} / \mathrm{B}$ population difference between the $\mathrm{dC}$ and $\mathrm{dT}$ series, with $59 \%$ B- and $41 \%$ S-SMI for the $\mathrm{dC}$ series and $86 \%$ B- and 14\% S-SMI for the dT series (Figures 7 and 8, respectively; see also Figure S10). The ability of the lesion to stabilize the bulge structure was sequence dependent, which probably accounts for this difference. The planar and hydrophobic FAAF induces S-SMI and maintains direct molecular interactions with the $3^{\prime}$ next flanking $X$ - $Y$ base pair (G, Figure 11). ${ }^{27,28,31,50}$ The hydrogen bond strength of the $X$ - $Y$ base pair also plays a role, i.e., the three hydrogen-bonded C:G base pairs at the $X$ position better enable a stacking interaction with the lesion compared to the two hydrogen-bonded T:A base pairs. The stability of the $X$ - $Y$ base pair aids in accommodating the stacking of the bulky FAAF lesion into the pocket of the -2 SMI.

Thermodynamic results showed consistently higher values of $T_{\mathrm{m}}, \Delta H$, and $\Delta G$ for the $\mathrm{dC}$ compared to the dT series. The DSC data (Figure 5 and Table 1) were consistent with the SPR binding affinity data, which exhibited consistently higher RU intensities and slower dissociation rates $\left(k_{\mathrm{d}}\right)$ for the $\mathrm{dC}$ series throughout TLS. The effect of the $3^{\prime}$-next flanking base sequence was reinforced by the ICD results (Figure 6). The $\mathrm{dC}$ series showed a gradual increase in ellipticity at $270 \mathrm{~nm}$ during the $\mathrm{n}-1 \rightarrow \mathrm{n} \rightarrow \mathrm{n}+1$ progression, indicating progressive strengthening of base stacking, whereas no such change was noted in the dT series. Finally, the FAAF-modified -2 SMI at $\mathrm{n}+6$ exhibited consistently greater stability relative to the fully paired counterparts ( $T_{\mathrm{m}} 10.5$ to $11.7{ }^{\circ} \mathrm{C}$ and $\Delta \Delta G-2.6$ to $-3.2 \mathrm{kcal} / \mathrm{mol}$; Tables S1-S2). Thermal stability increased as bulge formation matured from $\mathrm{n}+1$ to $\mathrm{n}+6$, and this trend persisted throughout TLS. The greater proportion of S-SMI in the $\mathrm{dC}$ compared to the dT series ( $41 \%$ vs $14 \%$ ) is consistent with Broschard's plasmid studies. ${ }^{27} \mathrm{In}$ those reports, frameshift mutagenesis was more likely when $X$ was C or A and least likely when $X$ was T. In other words, the stability of the bulged-out structures and the subsequent elongation determine the propensity for frameshift mutagenesis.

\section{Biological Relevance.}

In general, bulky DNA lesions are a strong replication block to various E. coli DNA polymerases (pol I, Klenow fragment $\mathrm{exo}^{-}$, pol $\mathrm{II} \mathrm{exo}^{-}$) in CG-dinucleotide repeat sequences such as the NarI recognition sequence. For example, pol $\mathrm{II} \mathrm{exo}^{-}$is responsible for -2 frameshifts induced by the potent mutagen AAF or related arylamine analogues. ${ }^{28} \mathrm{~A} \mathrm{Y}$ - 
family bypass DNA polymerase is known to utilize its spacious active site to accommodate and bypass bulky DNA lesions, which triggers a SMI driven frameshift mutation. ${ }^{18,38,39}$ The resulting SMI is stabilized by various chemical interactions within the binding pocket and will hinder translocation during TLS. ${ }^{18,36,56}$ For example, Schorr and Carell ${ }^{41}$ showed that frameshift formation is triggered by the unstable base pairing of the AAF lesion with the correct incoming $\mathrm{dC}$. Such configurations have been observed in replicative and bypass polymerases. ${ }^{18,38,39,56}$ To this end, we reported the structures of the FAAF-modified Nartsequence corresponding to $-1,-2$, and -3 deletion duplexes. ${ }^{33}$ These SMIs exist in a mixture of B- and S-SMI conformers, with the population of the S conformer and the thermodynamic stability being in the order of $-1>-2>-3$. Vyas and co-workers ${ }^{37}$ have recently obtained crystals of the complex of Dpo4 and DNA containing templating of the 1,8-diaminopyrene dG lesion in the presence of dCTP. The ternary structure showed that the bulky planar pyrene is sandwiched between the nascent and junction base pairs, while the modified guanine is exposed in the major groove. This configuration enables an incoming dCTP to form a Watson-Crick base pair with $\mathrm{dG}$, two nucleotides upstream from the lesion site, creating a stable SMI complex for -2 deletion mutations. Taken together, our results in the present study emphasize the importance of the structutal/thermodynamic stability of SMI and provide conformation insights into the thermodynamic mechanism of frameshift mutation.

\section{Summary.}

We have developed a TLS model for AAF-induced -2 frameshift mutagenesis (Figure 11), providing conformational and thermodynamic details of how a frameshift is triggered by the insertion of a correct dC opposite the bulky AAF- $\mathrm{dG}_{3}$. SMIs at the Nart site (5'-

$\mathrm{CG}_{1} \mathrm{G}_{2} \mathrm{CG}_{3} * \mathrm{C} X-3^{\prime}$ ) were systematically examined by spectroscopic, calorimetric, and binding studies. We found that instability of the $\mathrm{AAF}-\mathrm{dG}_{3}: \mathrm{dC}$ pair at the replication fork promotes slippage to form a $\mathrm{G}^{*} \mathrm{C}$ bulge-out structure, in which the $\mathrm{GC}$ end of the primer pairs with the complementary upstream CG sequence on the template strand. This misalignment produces a $\mathrm{G}^{*} \mathrm{C}$ bulge-out structure that comprises the unique $\mathrm{S}$ - and B-SMI bulge conformations. The results indicate the superior stability of the S-over the B-SMI conformer during TLS and the dependence of their population ratios on the $3^{\prime}$-next flanking base $X$ throughout TLS. A detailed understanding of the SMI structures and their sequence dependence may serve as a catalytic impetus to advance the conformational determination of such structures within DNA polymerase complexes. ${ }^{57}$

\section{Supplementary Material}

Refer to Web version on PubMed Central for supplementary material.

\section{ACKNOWLEDGMENTS}

We thank Dr. V. G. Vaidyanathan Ganesan for technical help and guidance. This research was also made possible in part by the use of the RI-INBRE Research Core Facility supported by an Institutional Development Award (IDeA) from the National Institute of General Medical Sciences of the National Institutes of Health under grant number P20GM103430.

Funding 
This research is supported by a NIH/NCI grant (R01CA098296).

\section{ABBREVIATIONS}

AF

AAF

DSC

FAAF

${ }^{19}$ F NMR

FP

ICD

SMI

SPR

TLS
$N$-(2'-deoxyguanosin-8-yl)-2-aminofluorene

$N$-(2'- deoxyguanosin-8-yl)-2-acetylaminofluorene

differential scanning calorimetry

$N$-(2'-deoxyguanosin-8-yl)-7-fluo-ro-2-acetylaminofluorene

fluorine nuclear magnetic resonance

fully paired

induced circular dichroism

slipped mutagenic intermediate

surface plasmon resonance

translesion synthesis

\section{REFERENCES}

(1). Luch A (2005) Nature and nurture - lessons from chemical carcinogenesis. Nat. Rev. Cancer 5, 113-125. [PubMed: 15660110]

(2). Besaratinia A, and Tommasi S (2013) Genotoxicity of tobacco smoke-derived aromatic amines and bladder cancer: current state of knowledge and future research directions. FASEB J. 27, 2090-2100. [PubMed: 23449930]

(3). Juricek L, Bui LC, Busi F, Pierre S, Guyot E, Lamouri A, Dupret JM, Barouki R, Coumoul X, and Rodrigues-Lima F (2015) Activation of the aryl hydrocarbon receptor by carcinogenic aromatic amines and modulatory effects of their N-acetylated metabolites. Arch. Toxicol. 89, 2403-2412. [PubMed: 25224404]

(4). Kovacic P, and Somanathan R (2014) Nitroaromatic compounds: Environmental toxicity, carcinogenicity, mutagenicity, therapy and mechanism. J. Appl Toxicol. 34, 810-824. [PubMed: 24532466]

(5). Beland FA, and Kadlubar FF (1990) Handbook of Experimental Pharmacology, Spring-Verlag, Heidelberg, Germany.

(6). Melchior WB Jr., Marques MM, and Beland FA (1994) Mutations induced by aromatic amine DNA adducts in pBR322. Carcinogenesis 15, 889-899. [PubMed: 8200092]

(7). Patnaik S, and Cho BP (2010) Structures of 2-acetylamino-fluorene modified DNA revisited: insight into conformational heterogeneity. Chem. Res. Toxicol. 23, 1650-1652. [PubMed: 20954689]

(8). Meneni S, Shell SM, Zou Y, and Cho BP (2007) Conformation-specific recognition of carcinogenDNA adduct in escherichia coli nucleotide excision repair. Chem. Res. Toxicol. 20, 6-10. [PubMed: 17226921]

(9). Patel DJ, Mao B, Gu Z, Hingerty BE, Gorin A, Basu AK, and Broyde S (1998) Nuclear magnetic resonance solution structures of covalent aromatic amine-DNA adducts and their mutagenic relevance. Chem. Res. Toxicol. 11, 391-407. [PubMed: 9585469]

(10). Liang F, Meneni S, and Cho BP (2006) Induced circular dichroism characteristics as conformational probes for carcinogenic aminofluorene-DNA adducts. Chem. Res. Toxicol. 19, 1040-1043. [PubMed: 16918242] 
(11). Meneni S, Liang F, and Cho BP (2007) Examination of the Long-range Effects of Aminofluorene-induced Conformational Heterogeneity and Its Relevance to the Mechanism of Translesional DNA Synthesis. J. Mol. Biol. 366, 1387-1400 Erratum, 1398, 1786. [PubMed: 17217958]

(12). Jain V, Hilton B, Lin B, Patnaik S, Liang F, Darian E, Zou Y, Mackerell AD Jr., and Cho BP (2013) Unusual sequence effects on nucleotide excision repair of arylamine lesions: DNA bending/distortion as a primary recognition factor. Nucleic Acids Res. 41, 869-880. [PubMed: 23180767]

(13). Jain V, Hilton B, Patnaik S, Zou Y, Chiarelli MP, and Cho BP (2012) Conformational and thermodynamic properties modulate the nucleotide excision repair of 2-aminofluorene and 2acetylamino-fluorene dG adducts in the NarI sequence. Nucleic Acids Res. 40, 3939-3951. [PubMed: 22241773]

(14). Jain V, Vaidyanathan VG, Patnaik S, Gopal S, and Cho BP (2014) Conformational insights into the lesion and sequence effects for arylamine-induced translesion DNA synthesis: ${ }^{19} \mathrm{~F} \mathrm{NMR}$, surface plasmon resonance, and primer kinetic studies. Biochemistry 53, 4059-4071. [PubMed: 24915610]

(15). Hsu GW, Kiefer JR, Burnouf D, Becherel OJ, Fuchs RP, and Beese LS (2004) Observing translesion synthesis of an aromatic amine DNA adduct by a high-fidelity DNA polymerase. J. Biol. Chem. 279, 50280-50285. [PubMed: 15385534]

(16). Belguise-Valladier P, and Fuchs RP (1991) Strong sequence-dependent polymorphism in adductinduced DNA structure: analysis of single N-2-acetylaminofluorene residues bound within the NarI mutation hot spot. Biochemistry 30, 10091-10100. [PubMed: 1931941]

(17). Lambert IB, Napolitano RL, and Fuchs RP (1992) Carcinogen-induced frameshift mutagenesis in repetitive sequences. Proc. Natl. Acad. Sci U. S. A. 89, 1310-1314. [PubMed: 1741385]

(18). Rechkoblit O, Kolbanovskiy A, Malinina L, Geacintov NE, Broyde S, and Patel DJ (2010) Mechanism of error-free and semitargeted mutagenic bypass of an aromatic amine lesion by Yfamily polymerase Dpo4. Nat. Struct. Mol. Biol. 17, 379-388. [PubMed: 20154704]

(19). Shibutani S, Suzuki N, and Grollman AP (1998) Mutagenic specificity of (acetylamino)fluorenederived DNA adducts in mammalian cells. Biochemistry 37, 12034-12041. [PubMed: 9724514]

(20). Shibutani S, Suzuki N, Tan X, Johnson F, and Grollman AP (2001) Influence of flanking sequence context on the mutagenicity of acetylaminofluorene-derived DNA adducts in mammalian cells. Biochemistry 40, 3717-3722. [PubMed: 11297440]

(21). Grollman AP, and Shibutani S (1994) Mutagenic specificity of chemical carcinogens as determined by studies of single DNA adducts. IARC Sci. Publ, 385-397. [PubMed: 7806328]

(22). Tan X, Suzuki N, Grollman AP, and Shibutani S (2002) Mutagenic events in Escherichia coli and mammalian cells generated in response to acetylaminofluorene-derived DNA adducts positioned in the Nar I restriction enzyme site. Biochemistry 41, 14255-14262. [PubMed: 12450390]

(23). Hoffmann GR, and Fuchs RPP (1997) Mechanisms of Frameshift Mutations: Insight from Aromatic Amines. Chem. Res. Toxicol. 10, 347-359. [PubMed: 9114969]

(24). Burnouf D, Koehl P, and Fuchs RP (1989) Single adduct mutagenesis: strong effect of the position of a single acetylamino-fluorene adduct within a mutation hot spot. Proc. Natl. Acad. Sci. U. S. A. 86,4147-4151. [PubMed: 2657743]

(25). Veaute X, and Fuchs RP (1991) Polymorphism in N-2-acetylaminofluorene induced DNA structure as revealed by DNase I footprinting. Nucleic Acids Res. 19, 5603-5606. [PubMed: 1945836]

(26). Thomas DC, Veaute X, Kunkel TA, and Fuchs RP (1994) Mutagenic replication in human cell extracts of DNA containing site-specific N-2-acetylaminofluorene adducts. Proc. Natl. Acad. Sci. U. S. A. 91, 7752-7756. [PubMed: 8052656]

(27). Broschard TH, Koffel-Schwartz N, and Fuchs RP (1999) Sequence-dependent modulation of frameshift mutagenesis at NarI-derived mutation hot spots. J. Mol. Biol. 288, 191-199. [PubMed: 10329136]

(28). Fuchs RP, and Fujii S (2007) Translesion synthesis in Escherichia coli: lessons from the NarI mutation hot spot. DNA Repair 6, 1032-1041. [PubMed: 17403618] 
(29). Koffel-Schwartz N, and Fuchs RP (1995) Sequence determinants for -2 frameshift mutagenesis at NarI-derived hot spots. J. Mol. Biol. 252, 507-513. [PubMed: 7563069]

(30). Garcia A, Lambert IB, and Fuchs RP (1993) DNA adduct-induced stabilization of slipped frameshift intermediates within repetitive sequences: implications for mutagenesis. Proc. Natl. Acad. Sci. U. S. A. 90, 5989-5993. [PubMed: 8327472]

(31). Roy D, Hingerty BE, Shapiro R, and Broyde S (1998) A slipped replication intermediate model is stabilized by the syn orientation of N-2-aminofluorene- and N-2-(acetyl)aminofluorene-modified guanine at a mutational hotspot. Chem. Res. Toxicol. 11,1301-1311. [PubMed: 9815190]

(32). Koffel-Schwartz N, Verdier JM, Bichara M, Freund AM, Daune MP, and Fuchs RP (1984) Carcinogen-induced mutation spectrum in wild-type, uvrA and umuC strains of Escherichia coli. Strain specificity and mutation-prone sequences. J. Mol. Biol. 177, 33-51. [PubMed: 6379196]

(33). Sandineni A, Lin B, MacKerell AD Jr., and Cho BP (2013) Structure and thermodynamic insights on acetylaminofluorene-modified deletion DNA duplexes as models for frameshift mutagenesis. Chem. Res. Toxicol. 26, 937-951. [PubMed: 23688347]

(34). Gill JP, and Romano LJ (2005) Mechanism for N-acetyl-2-aminofluorene-induced frameshift mutagenesis by Escherichia coli DNA polymerase I (Klenow fragment). Biochemistry 44, 15387-15395. [PubMed: 16285743]

(35). Dutta S, Li Y, Johnson D, Dzantiev L, Richardson CC, Romano LJ, and Ellenberger T (2004) Crystal structures of 2-acetylaminofluorene and 2-aminofluorene in complex with T7 DNA polymerase reveal mechanisms of mutagenesis. Proc. Natl Acad. Sci. U. S. A. 101, 1618616191. [PubMed: 15528277]

(36). Kirouac KN, Basu AK, and Ling H (2013) Replication of a carcinogenic nitropyrene DNA lesion by human Y-family DNA polymerase. Nucleic Acids Res. 41, 2060-2071. [PubMed: 23268450]

(37). Vyas R, Efthimiopoulos G, Tokarsky EJ, Malik CK, Basu AK, and Suo Z (2015) Mechanistic Basis for the Bypass of a Bulky DNA Adduct Catalyzed by a Y-Family DNA Polymerase. J. Am. Chem. Soc. 137, 12131-12142. [PubMed: 26327169]

(38). Brenlla A, Rueda D, and Romano LJ (2015) Mechanism of aromatic amine carcinogen bypass by the Y-family polymerase, Dpo4. Nucleic Acids Res. 43, 9918-9927. [PubMed: 26481355]

(39). Schorr S, Schneider S, Lammens K, Hopfner K-P, and Carell T (2010) Mechanism of replication blocking and bypass of Y-family polymerase $\{$ eta $\}$ by bulky acetylaminofluorene DNA adducts. Proc. Natl. Acad. Sci. U. S.A. 107, 20720-20725. [PubMed: 21076032]

(40). Choi JY, Stover JS, Angel KC, Chowdhury G, Rizzo CJ, and Guengerich FP (2006) Biochemical basis of genotoxicity of heterocyclic arylamine food mutagens: Human DNA polymerase eta selectively produces a two-base deletion in copying the N2-guanyl adduct of 2-amino-3methylimidazo[4,5-f]quinoline but not the C8 adduct at the NarI G3 site. J. Biol. Chem. 281, 25297-25306. [PubMed: 16835218]

(41). Schorr S, and Carell T (2010) Mechanism of acetylamino-fluorene-dG induced frameshifting by polymerase eta. ChemBioChem 11, 2534-2537. [PubMed: 21064171]

(42). Cho BP, and Zhou L (1999) Probing the conformational heterogeneity of the acetylaminofluorene-modified 2 -deoxyguanosine and DNA by ${ }^{19}$ F NMR spectroscopy. Biochemistry 38, 7572-7583. [PubMed: 10360955]

(43). Meneni SR, D’Mello R, Norigian G, Baker G, Gao L, Chiarelli MP, and Cho BP (2006) Sequence effects of aminofluorene-modified DNA duplexes: thermodynamic and circular dichroism properties. Nucleic Acids Res. 34, 755-763. [PubMed: 16449208]

(44). Chakrabarti MC, and Schwarz FP (1999) Thermal stability of PNA/DNA and DNA/DNA duplexes by differential scanning calorimetry. Nucleic Acids Res. 27, 4801-4806. [PubMed: 10572181]

(45). Jain N, Li Y, Zhang L, Meneni SR, and Cho BP (2007) Probing the sequence effects on NarIinduced -2 frameshift mutagenesis by dynamic ${ }^{19} \mathrm{~F} \mathrm{NMR}, \mathrm{UV}$, and CD spectroscopy. Biochemistry 46, 13310-13321. [PubMed: 17960913]

(46). Jain N, Meneni S, Jain V, and Cho BP (2009) Influence of flanking sequence context on the conformational flexibility of aminofluorene-modified dG adduct in dA mismatch DNA duplexes. Nucleic Acids Res. 37, 1628-1637. [PubMed: 19151371] 
(47). Meneni SR, Shell SM, Gao L, Jurecka P, Lee W, Sponer J, Zou Y, Chiarelli MP, and Cho BP (2007) Spectroscopic and theoretical insights into sequence effects of aminofluorene-induced conformational heterogeneity and nucleotide excision repair. Biochemistry 46, 11263-11278. [PubMed: 17877372]

(48). Xu L, Vaidyanathan VG, and Cho BP (2014) Real-time surface plasmon resonance study of biomolecular interactions between polymerase and bulky mutagenic DNA lesions. Chem. Res. Toxicol. 27, 1796-1807. [PubMed: 25195494]

(49). Vaidyanathan VG, Xu L, and Cho BP (2012) Binary and ternary binding affinities between exonuclease-deficient Klenow fragment (Kf-exo(-)) and various arylamine DNA lesions characterized by surface plasmon resonance. Chem. Res. Toxicol. 25, 1568-1570. [PubMed: 22804627]

(50). Milhe C, Fuchs RP, and Lefevre JF (1996) NMRdata show that the carcinogen N-2acetylaminofluorene stabilises an intermediate of -2 frameshift mutagenesis in a region of high mutation frequency. Eur. J. Biochem. 235, 120-127. [PubMed: 8631318]

(51). Mao B, Gorin A, Gu Z, Hingerty BE, Broyde S, and Patel DJ (1997) Solution structure of the aminofluorene-intercalated conformer of the syn [AF]-C8-dG adduct opposite a-2 deletion site in the NarI hot spot sequence context. Biochemistry 36, 14479-14490. [PubMed: 9398167]

(52). Jain V, Hilton B, Lin B, Jain A, MacKerell AD Jr., Zou Y, and Cho BP (2013) Structural and thermodynamic insight into Escherichia coli UvrABC-mediated incision of cluster diacetylamino-fluorene adducts on the NarI sequence. Chem. Res. Toxicol. 26, 1251-1262. [PubMed: 23841451]

(53). Liang F, and Cho BP (2007) Probing the thermodynamics of aminofluorene-induced translesion DNA synthesis by differential scanning calorimetry. J. Am. Chem. Soc. 129, 12108-12109. [PubMed: 17867689]

(54). Zhou L, Rajabzadeh M, Traficante DD, and Cho BP (1997) Conformational Heterogeneity of Arylamine-Modified DNA: 19F NMR Evidence. J. Am. Chem. Soc. 119, 5384-5389.

(55). Broyde S, and Hingerty BE (1987) Visualization of an AAF induced frameshift mutation: molecular views of base displacement in B-DNA from minimized potential energy calculations. Nucleic Acids Res. 15, 6539-6552. [PubMed: 3627997]

(56). Donny-Clark K, Shapiro R, and Broyde S (2009) Accommodation of an N-(deoxyguanosin-8yl)-2-acetylaminofluorene adduct in the active site ofhuman DNA polymerase iota: Hoogsteen or Watson-Crick base pairing? Biochemistry 48, 7-18. [PubMed: 19072536]

(57). Broyde S, Wang L, Zhang L, Rechkoblit O, Geacintov NE, and Patel DJ (2008) DNA adduct structure-function relationships: comparing solution with polymerase structures. Chem. Res. Toxicol. 21, 45-52. [PubMed: 18052109] 
(a)<smiles>[X]c1ccc2c(c1)Cc1cc(N([R])c3nc4c(=O)[nH]c(N)nc4n3C3OCCC3OCOC)ccc1-2</smiles>

$\mathrm{R}=\mathrm{H}, \mathrm{X}=\mathrm{H} ; \mathbf{A F}$

$\mathrm{R}=\mathrm{Ac}, \mathrm{X}=\mathrm{H}$; AAF

$\mathrm{R}=\mathrm{Ac}, \mathrm{X}=\mathrm{F}$; FAAF

(b)
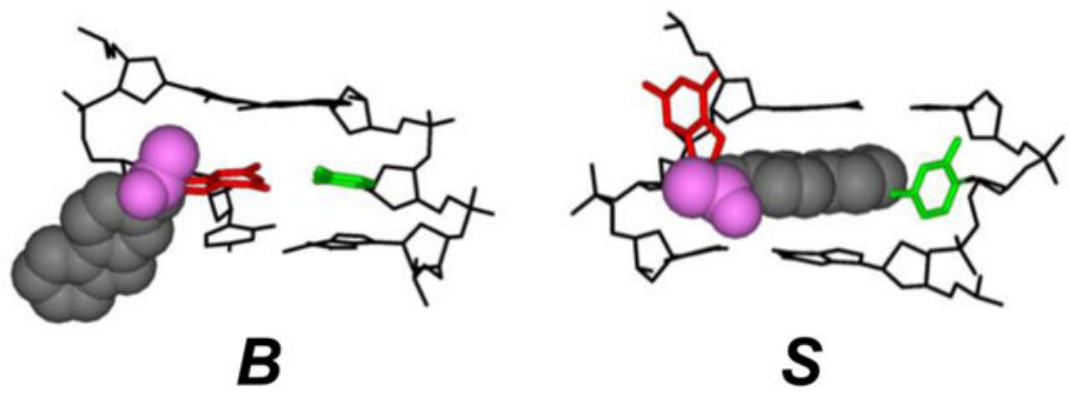

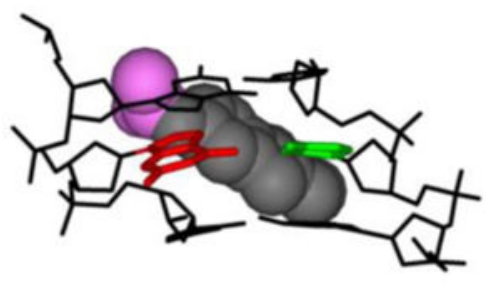

W

Figure 1.

(a) Structures of AF [ $N-\left(2^{\prime}\right.$-deoxyguanosm-8-yl)-2-aminofluorene], $\mathrm{AAF}$ [ $N-\left(2^{\prime}-\right.$ deoxyguanosin-8-yl)-2-acetylaminofluorene], and FAAF [ $N$-(2'-deoxyguanosm-8-yl)-7fluoro-2-acetylaminofluorene]. (b) Major groove views of the B, S, and $\mathrm{W}$ conformers of AAF. Color code: modified-dG (red stick), dC (green stick) opposite the lesion site, aminofluorene (gray CPK), and $N$-acetyl (pink CPK). 
(a) Fully Paired (FP)
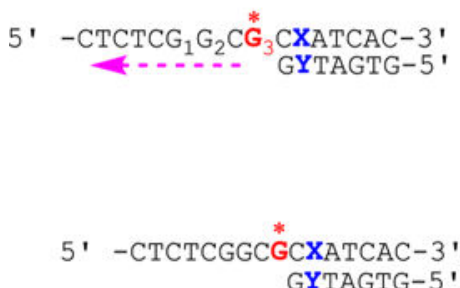
GYTAGTG-5 ' n-1 CGYTAGTG-5' n GCGYTAGTG-5 ' n+1 CGCGYTAGTG-5' $\mathbf{n}+\mathbf{2}$ CCGCGYTAGTG-5' $\mathbf{n + 3}$

3' -GAGAGCCGCGYTAGTG-5' $\mathbf{n}+\mathbf{8}$ (b) Slipped Mutagenic Intermediate (SMI)
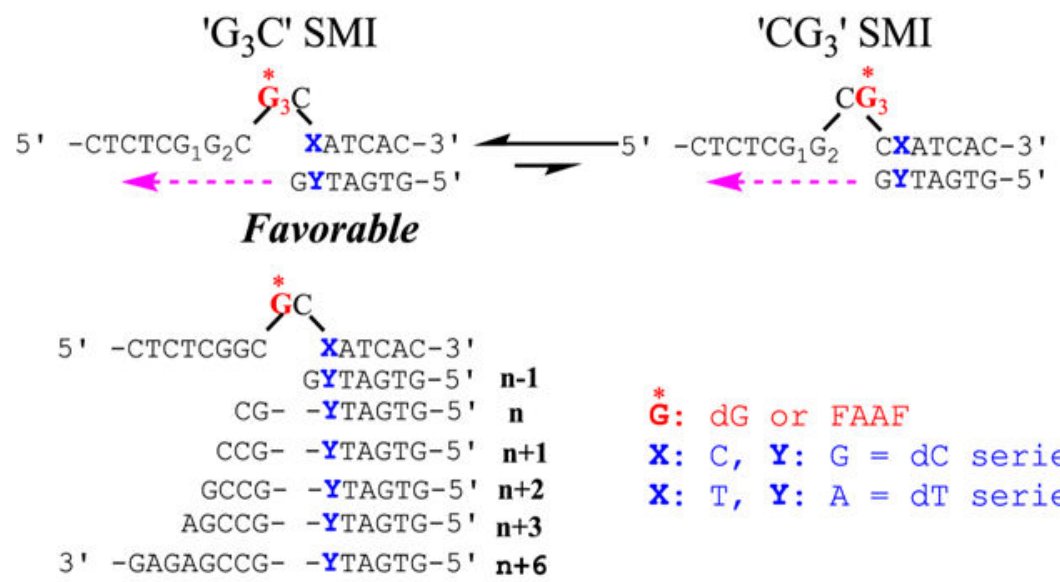

G: $d G$ or FAAF

$\mathbf{X}: C, \mathbf{Y}: G=d C$ series

$\mathbf{X}: T, \mathbf{Y}: A=d T$ series

\section{FP/dC; FP/dT; FAAF-FP/dC; FAAF-FP/dT}

\section{SMI/dC; SMI/dT; FAAF-SMI/dC; FAAF-SMI/dT}

Figure 2.

Translesion synthesis (TLS) models for (a) the fully paired (FP) and (b) slipped mutagenic intermediate (SMI) sequences. Red $\mathrm{G}_{3} *$ represents either the unmodified control or FAAFmodified guanine. The $3^{\prime}$-next flanking base $\mathbf{X}$ (blue) is $\mathrm{dC}$ or dT, which base pairs with $\mathbf{Y}$ (blue, $\mathrm{dG}$ or $\mathrm{dA}$ ), in the primer strand ( $\mathrm{dC}$ or $\mathrm{dT}$ series, respectively). Incorporation of the correct $\mathrm{dC}$ opposite the FAAF lesion can lead to a $\mathrm{G}^{*} \mathrm{C}$ or $\mathrm{CG}^{*}-2$ bulge-out SMI structure. The FAAF at $\mathrm{G}_{3}$ in the $N a r$ sequence favors the $\mathrm{G}^{*} \mathrm{C}$ over $\mathrm{CG}^{*} \mathrm{SMI}$ (see text). The ss/ds template-primer TLS $(\mathrm{n}-1 \sim \mathrm{n}+8)$ for FP are FP/dC, dC series; FP/dT, dT series; FAAFFP/dC, FAAF-modified dC series; FAAF-FP/dT, FAAF-modified dT series. The ss/ds template-primer TLS $(\mathrm{n}-1 \sim \mathrm{n}+6)$ for SMI are SMI/dC, dC series; SMI/dT, dT series; FAAF-SMI/dC, FAAF-modified dC series; FAAF-SMI/dT, FAAF-modified dT series. 
(a)

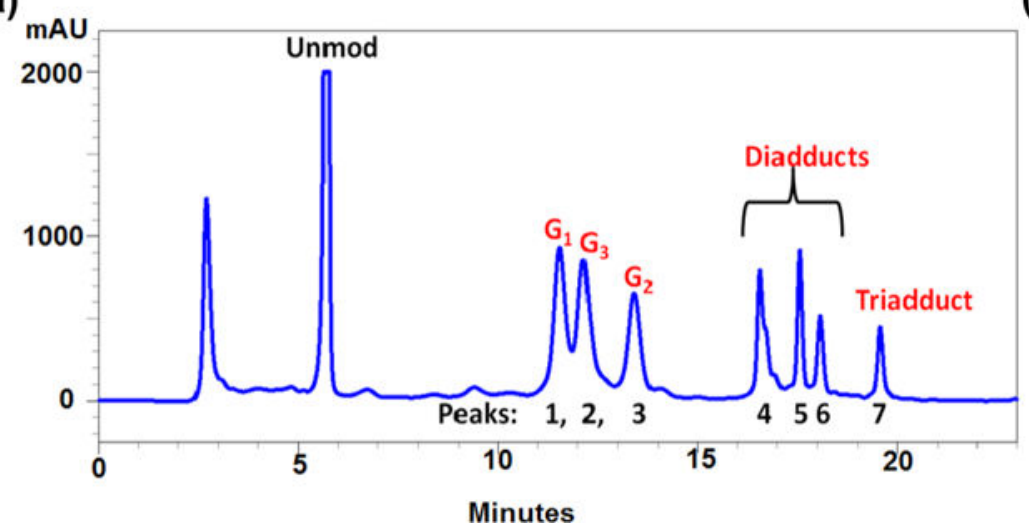

(b)

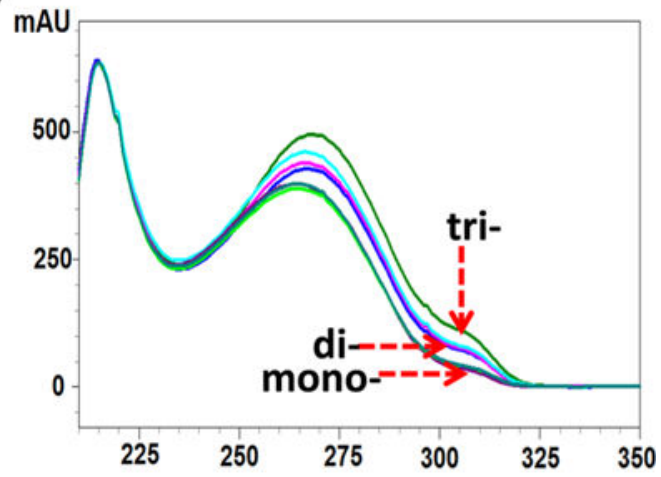

Figure 3.

(a) HPLC chromatogram of a mixture derived from the reaction between the Narl-dC 16mer sequence and activated FAAF ( $N$-(trifluoroacetyl)- $N$-acetoxy-7-fluoro-2-

aminofluorene). HPLC mobile phase: $3-9 \%$ acetonitrile for a 5 min linear gradient followed by $9-30 \%$ acetonitrile for a $20 \mathrm{~min}$ linear gradient in ammonium acetate buffer $(100 \mathrm{mM}$, $\mathrm{pH}$ 7.0) with a flow rate of $2.0 \mathrm{~mL} / \mathrm{min}$. Peaks 1,2, and 3: mono-FAAF adducts eluted in the 11-14 min range; peaks 4, 5, and 6, di-FAAF-adducts eluted in the 16-19 min range; and peak 7, tri-FAAF adduct eluted at 19.5 min. (b) Photodiode array UV spectra of FAAF adducts showing additive shoulder intensity in the 300-325 nm range. 

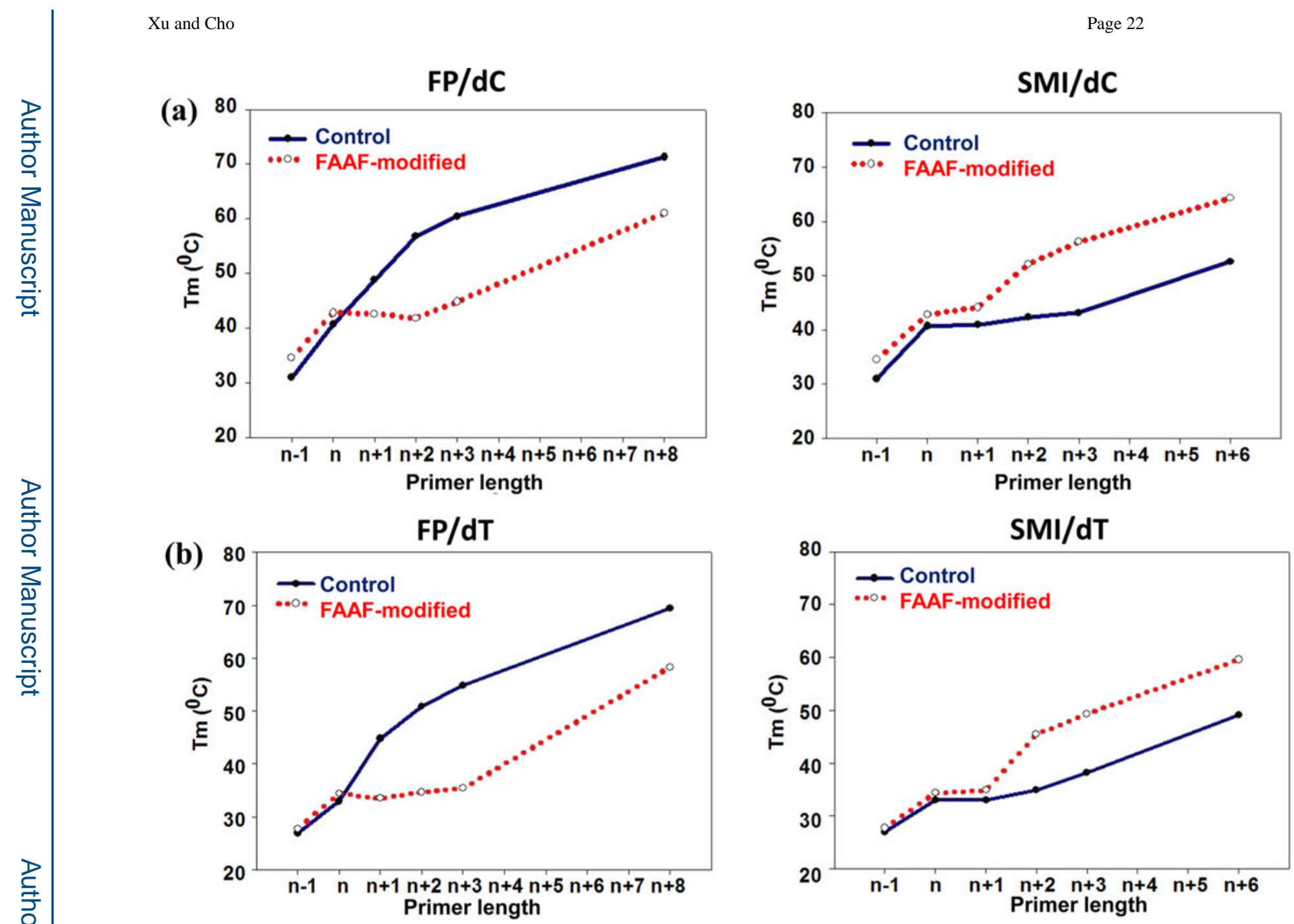

Figure 4.

UV melting (Tm) as a function of primer elongation for the fully paired $(\mathrm{FP})(\mathrm{n}-1 \sim \mathrm{n}+8)$ and slipped mutagenic intermediate $(S M I)(n-1 \sim n+6)$ in the $(a) d C$ and (b) dT series. See Figure 2 for full sequences. Unmodified controls are shown as blue lines, and FAAFmodified are shown as red dots. 
$\mathrm{SMI} / \mathrm{dC}$ (control)

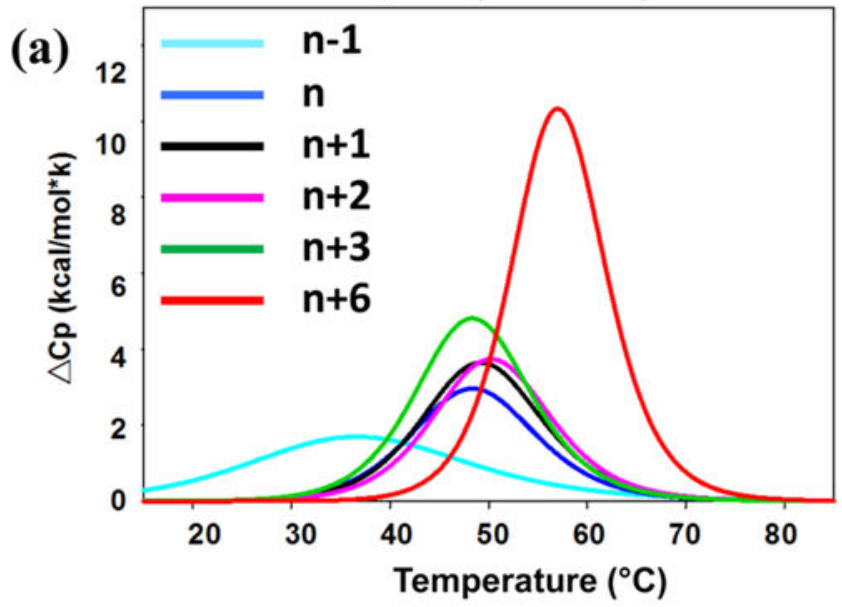

SMI/dT (control)

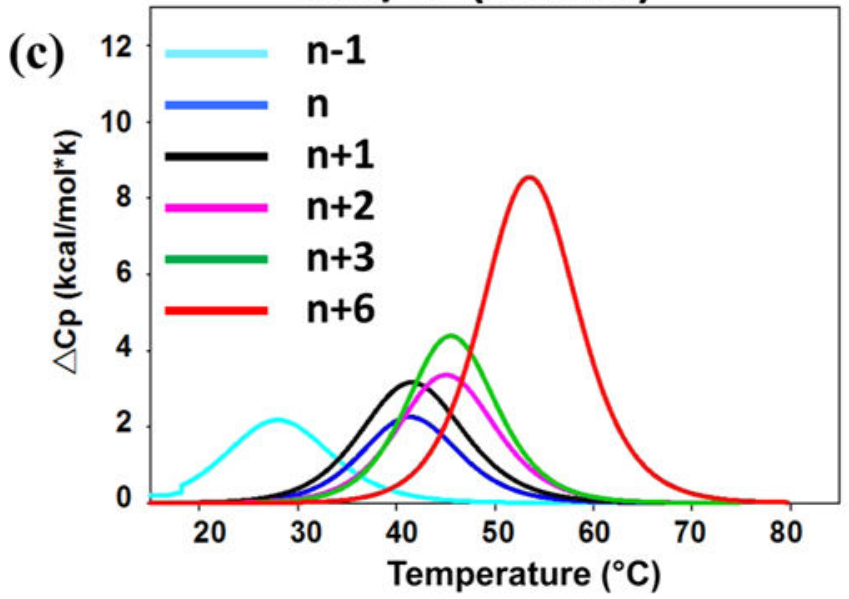

FAAF-SMI/dC

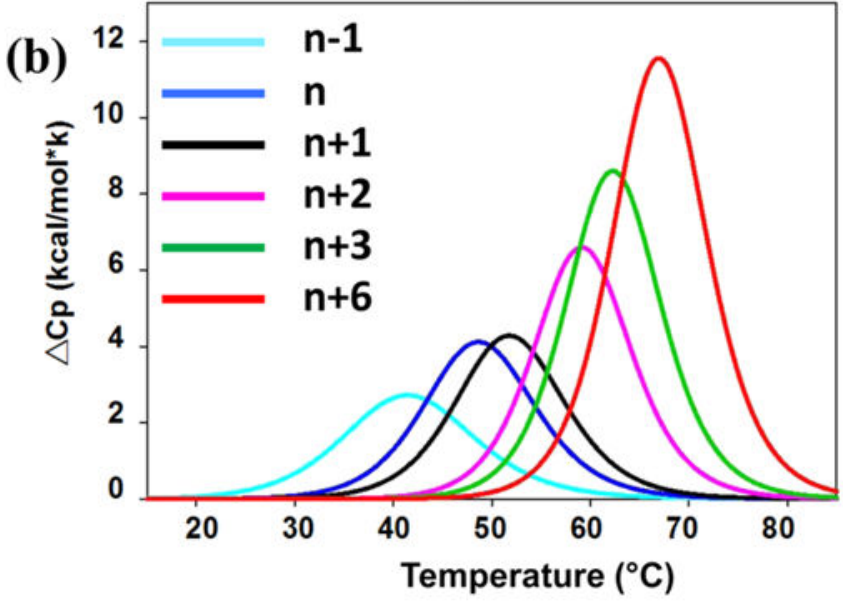

FAAF-SMI/dT

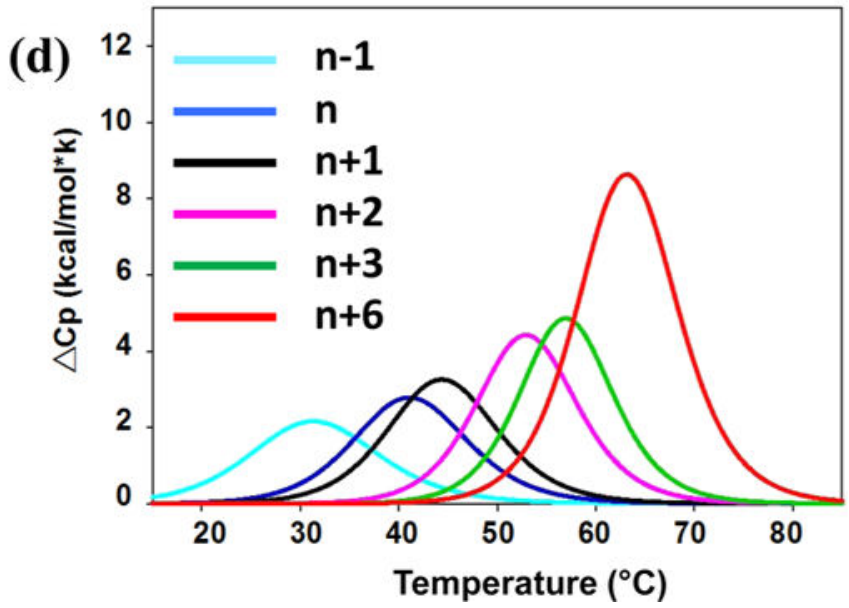

Figure 5.

DSC heat capacity $\left(\Delta C_{\mathrm{p}}\right)$ as a function of temperature $\left(15-85^{\circ} \mathrm{C}\right)$ for primer elongation of the control SMI (a and c) and FAAF-modified SMI (b and d) for the dC and dT series. See Figure 2 for full TLS sequences. Complementary strands are color-coded: cyan (n-1), blue $(n)$, black $(n+1)$, pink $(n+2)$, green $(n+3)$, and red $(n+6)$. The maximum point of DSC thermograms corresponds to the melting point $\left(T_{\mathrm{m}}\right)$, and areas under the curve represent enthalpy changes $(\Delta H)$. 
(a)

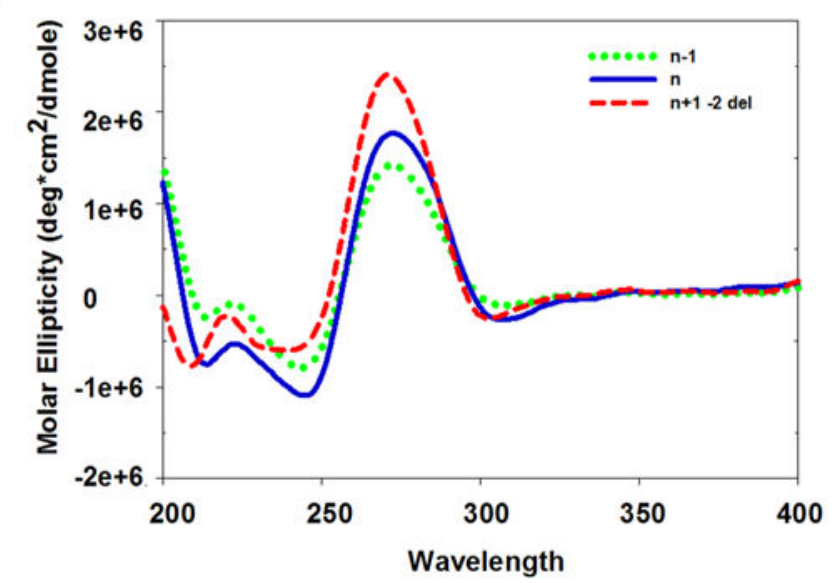

(b)

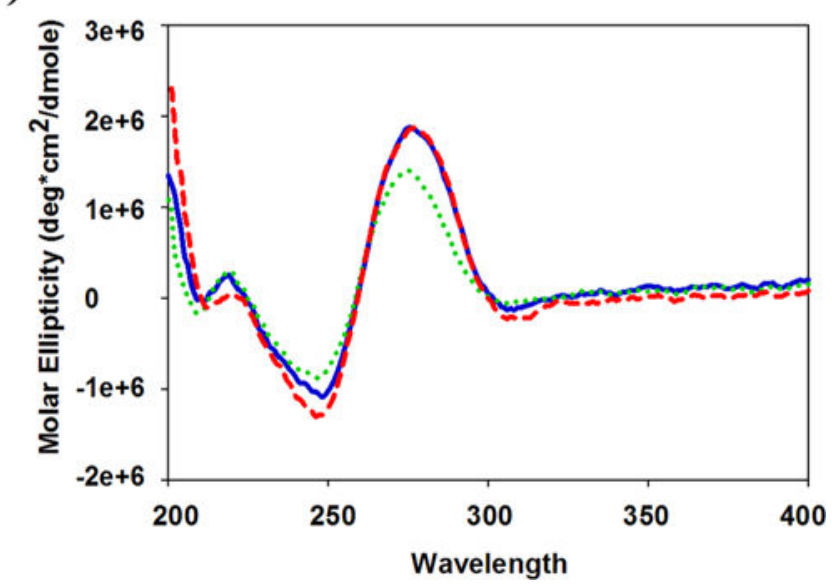

Figure 6.

Circular dichroism (CD) spectral overlays as a function of primer elongation for FAAFmodified SMI in the (a) dC and (b) dT series. Primers: green (n-1), blue (n), and red (n+1). 


\section{FAAF-SMI/dC}

n-1

$n+1$

$n+3$

$n+6$
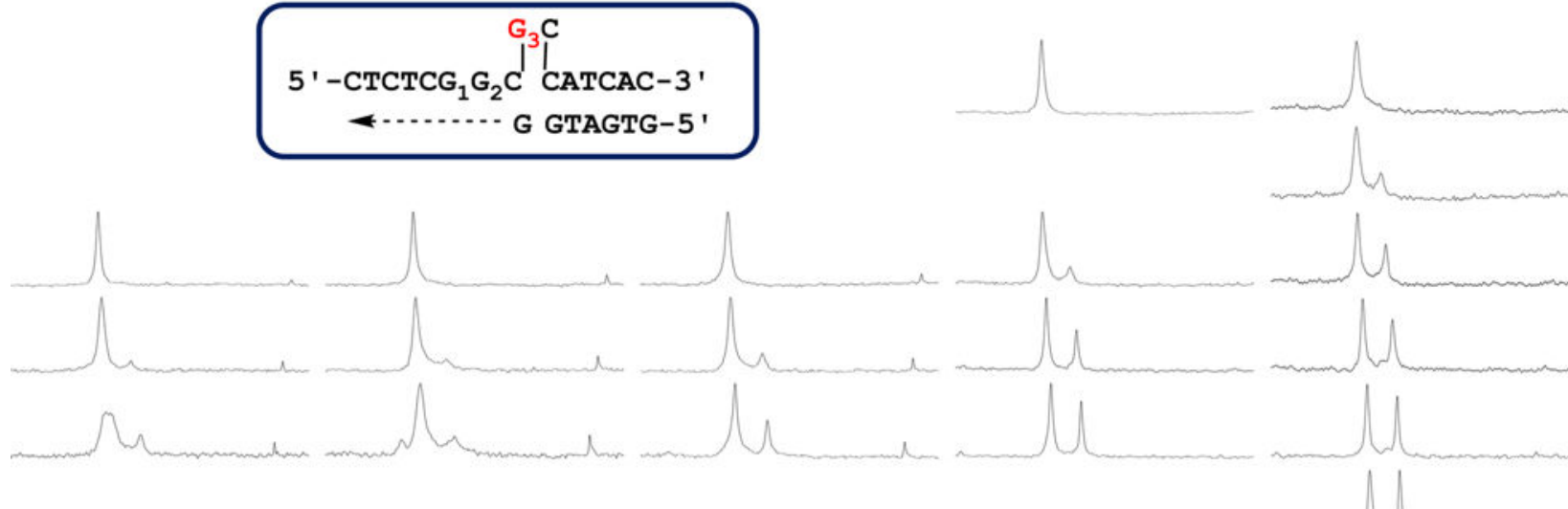

$70^{\circ} \mathrm{C}$
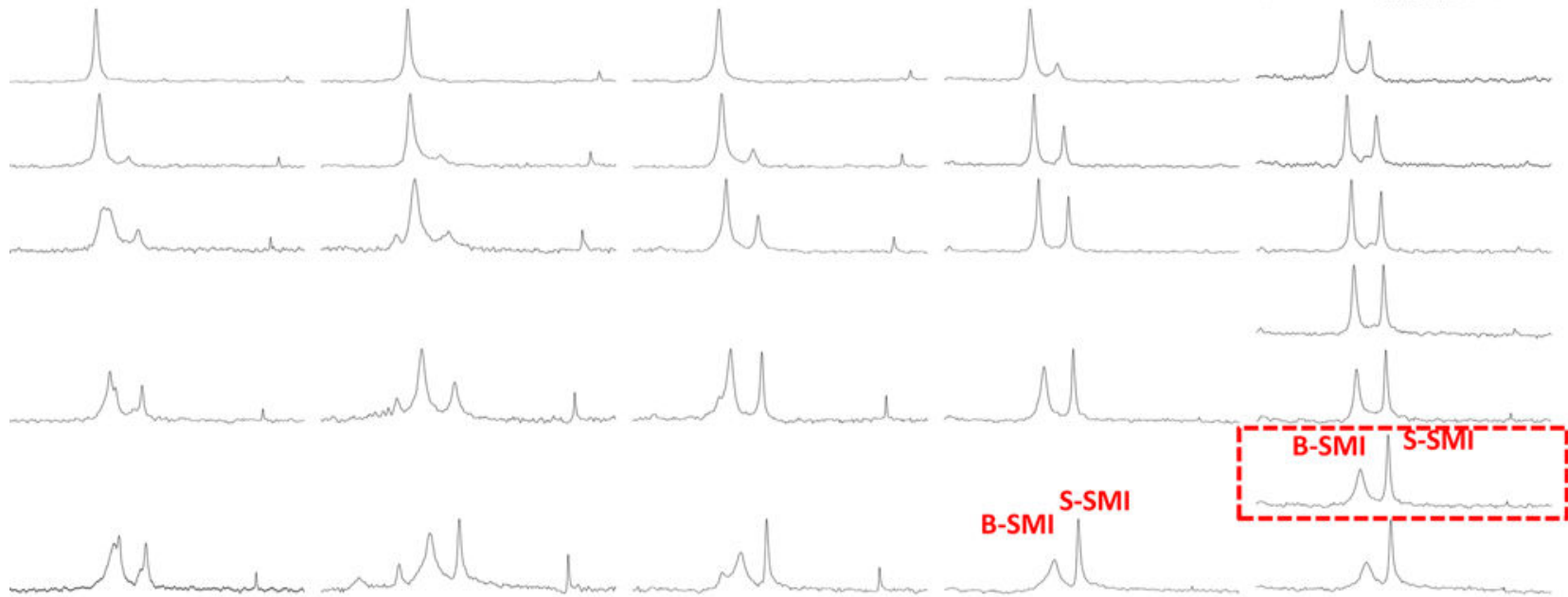

35

30
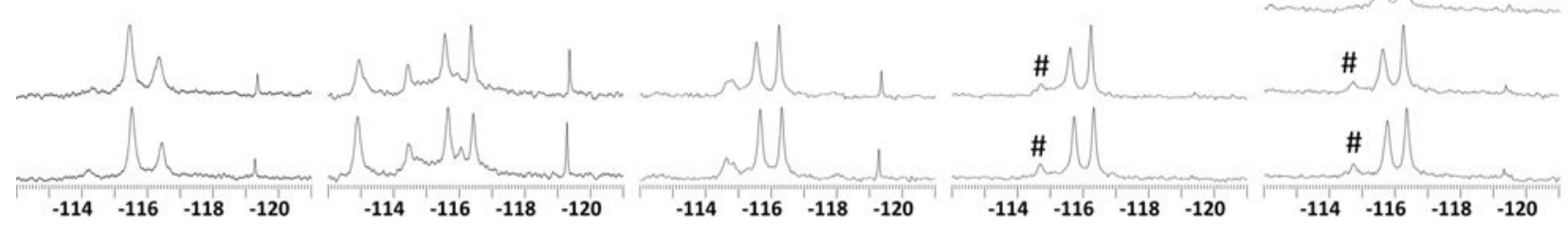

Figure 7.

Dynamic ${ }^{19} \mathrm{~F}$ NMR spectra $\left(5-70{ }^{\circ} \mathrm{C}\right)$ of various FAAF-SMI/dC primer-template duplexes $(n-1 \sim n+6)$. One hundred micromolar $\mathrm{G}_{3}$-FAAF modified 16-mer template was annealed with an equimolar amount of the respective primers to produce appropriate TLS duplexes (see Figure $2 \mathrm{~b}$ for full TLS sequences). The NMR samples were prepared in Shigemi tubes containing $250 \mu \mathrm{L}$ of NMR buffer $\left(10 \% \mathrm{D}_{2} \mathrm{O} / 90 \% \mathrm{H}_{2} \mathrm{O}, \mathrm{pH} 7.0,100 \mathrm{mM} \mathrm{NaCl}, 10 \mathrm{mM}\right.$ sodium phosphate, and $100 \mu \mathrm{M}$ EDTA). These primer-template TLS dupl exes exhibited a mixture of ${ }^{19} \mathrm{~F}$ signals, each representing a unique electronic environment. In all cases, the ${ }^{19} \mathrm{~F}$ signals above $60{ }^{\circ} \mathrm{C}$ coalesced into a sharp single peak at $-115 \mathrm{ppm}$, which indicates fast averaging of the denatured FAAF-residue. The relative S/B-SMI conformational ratios in the dotted box ( $\mathrm{n}+6 \mathrm{TLS}$ duplex at $25^{\circ} \mathrm{C}$ ) were obtained byline simulation (Figure S10): B $(59 \%)$ and $\mathrm{S}(41 \%)$. \# indicates unassigned minor conformers (see text).

Chem Res Toxicol. Author manuscript; available in PMC 2019 October 03. 


\section{FAAF-SMI/dT}
n-1
$n$
$n+1$
$n+3$
$n+6$

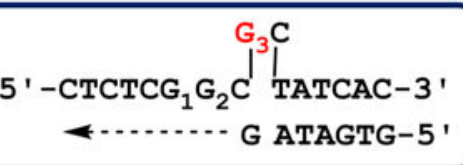

$70^{\circ} \mathrm{C}$
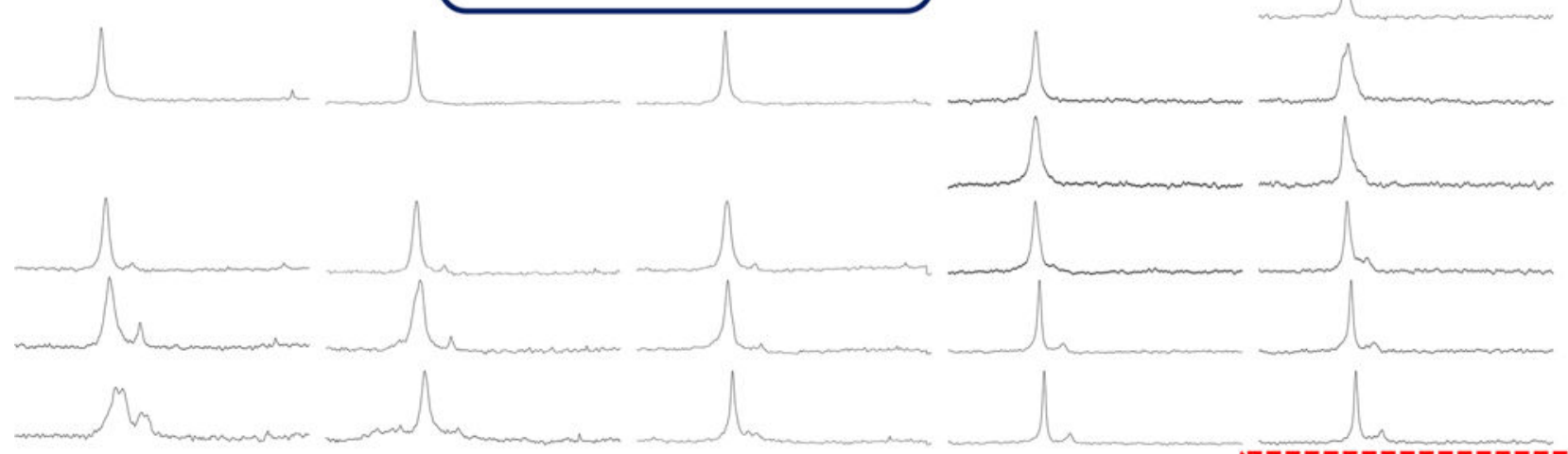

60
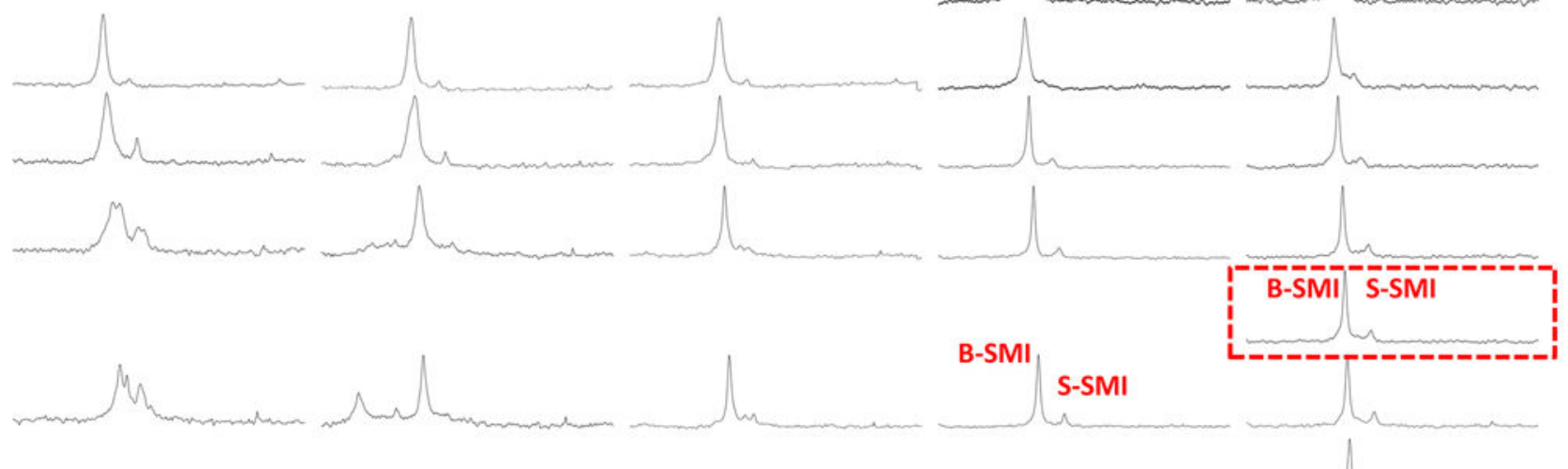

25

20
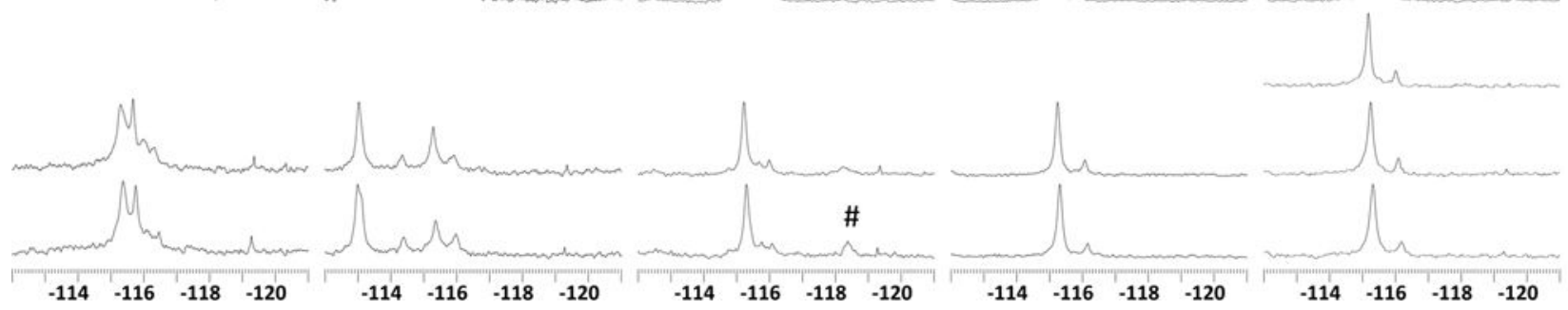

Figure 8.

Dynamic ${ }^{19} \mathrm{~F}$ NMR spectra $\left(5-70{ }^{\circ} \mathrm{C}\right)$ of the FAAF-SMI/dT template primer-template duplexes (n-1 +6). One hundred micromolar $\mathrm{G}_{3}$-FAAF modified 16-mer template was annealed with an equimolar amount of respective primers to produce appropriate TLS duplexes (see Figure $2 \mathrm{~b}$ for full TLS sequences). The NMR samples were prepared in Shigemi tubes containing $250 \mu \mathrm{L}$ of NMR buffer $\left(10 \% \mathrm{D}_{2} \mathrm{O} / 90 \% \mathrm{H}_{2} \mathrm{O}, \mathrm{pH} 7.0,100 \mathrm{mM}\right.$ $\mathrm{NaCl}, 10 \mathrm{mM}$ sodium phosphate, and $100 \mu \mathrm{M}$ EDTA). These primer-template TLS duplexes exhibited a mixture of ${ }^{19} \mathrm{~F}$ signals, each representing a unique electronic environment. In all cases, the ${ }^{19} \mathrm{~F}$ signals above $60{ }^{\circ} \mathrm{C}$ coalesced into a sharp single peak at $-115 \mathrm{ppm}$, which indicates fast averaging of the denatured FAAF-residue. The relative S/B-SMI conformation ratios in the dotted box $\left(\mathrm{n}+6 \mathrm{TLS}\right.$ duplex at $\left.25^{\circ} \mathrm{C}\right)$ were obtained by line simulation (Figure S10): B (86\%) and S (14\%). \# indicates unassigned minor conformers (see text).

Chem Res Toxicol. Author manuscript; available in PMC 2019 October 03. 

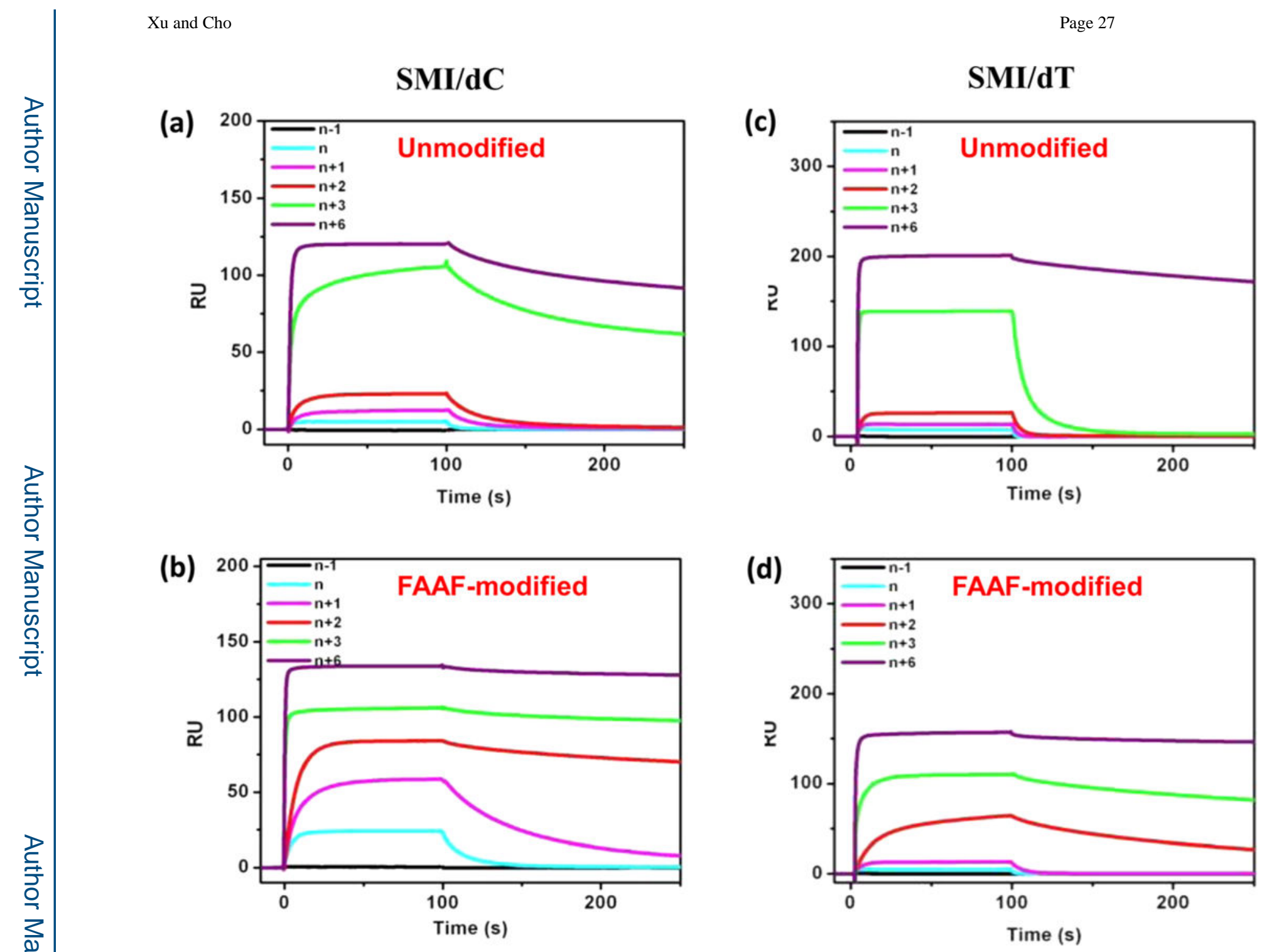

Figure 9.

SPR sensorgrams of unmodified and FAAF-modified SMI TLS: (a) SMI/dC, (b) FAAFSMI/dC, (c) SMI/dT, and (d) FAAF-SMI/dT. Primer concentrations were $25 \mathrm{nM}(\mathrm{n}-1$, black), $50 \mathrm{nM}$ (n, cyan), $75 \mathrm{nM}$ (n+1, pink), $100 \mathrm{nM}(\mathrm{n}+2$, red), and $150 \mathrm{nM}(\mathrm{n}+3$, green; $\mathrm{n}$ +6 , purple). In all cases, dissociation off rates starting at $100 \mathrm{~s}$ slowed significantly with increasing primer length. Relative intensity (RU) was disrupted at the $n \sim n+2$ segments of the SMI controls (a and c). This is contrasted to a gradual increase in RU for the FAAFmodified SMI (b and d), which indicates lesion-induced SMI stabilization. 
$n+1$

$n+2$

$n+3$

$n+6 / n+8$

(a) dC series
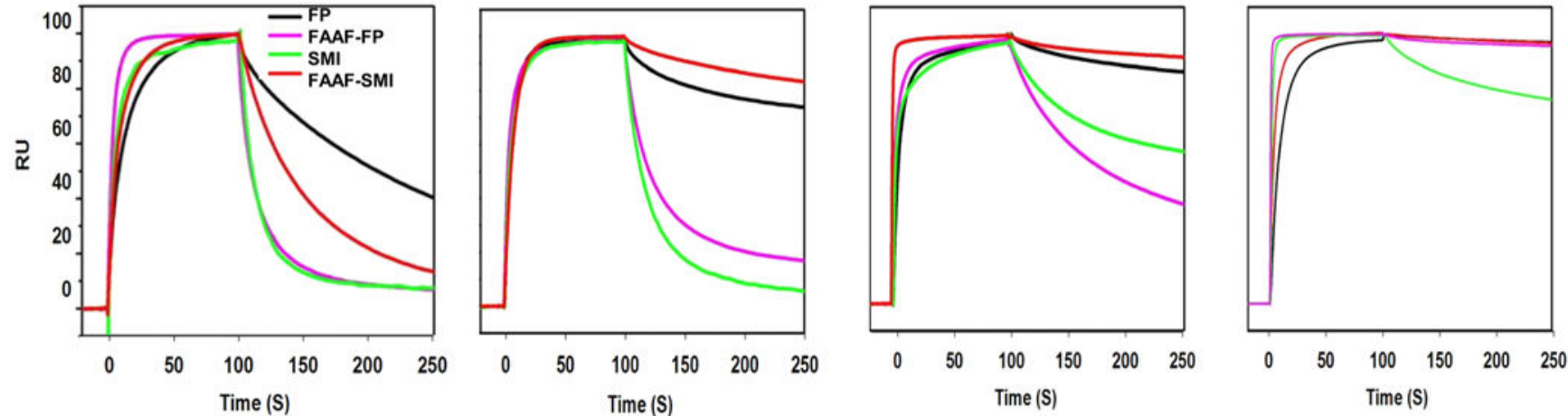

(b) dT series
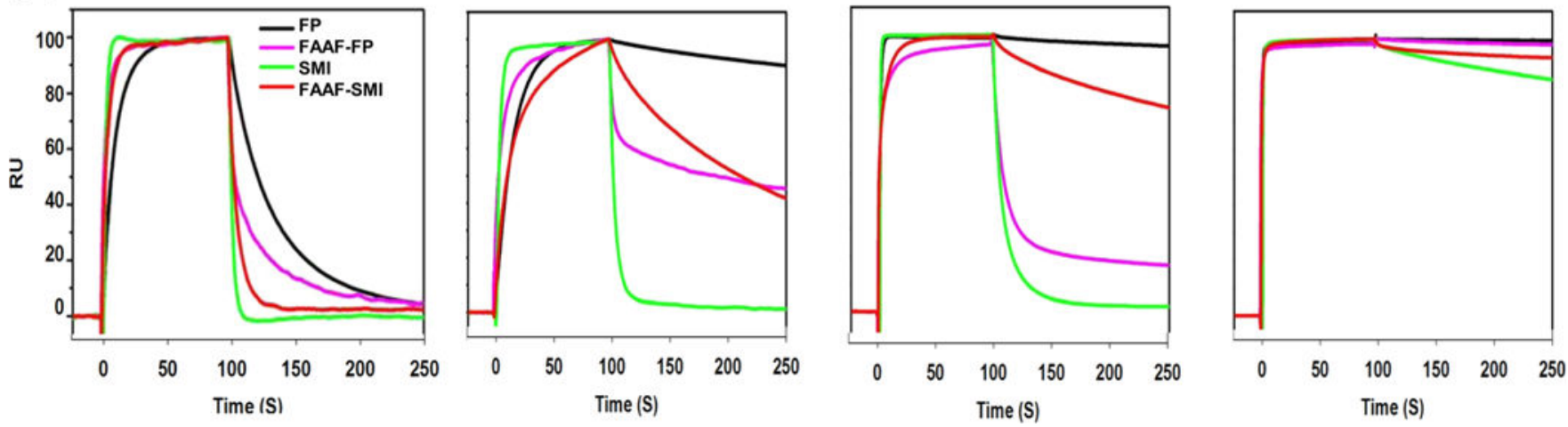

Figure 10.

Normalized SPR sensorgrams of four TLS models with different primer lengths: FP (black), FAAF-FP (pink), SMI (green), and FAAF-SMI (red) at $n+1, n+2, n+3$, and $n+6 / n+8$ positions for the (a) dC and (b) dT series. Dissociation of ss/ds primer-template duplexes begins at $100 \mathrm{~s}$ when the primer solution is no longer available, but only running buffer solution is flowing over the DNA immobilized chips. Different off rates are observed because of the different binding capacity of the primer-template duplexes. Slower dissociation indicates greater stability of the primer-template duplexes. For example, TLS duplex stability at $n+2$ of the dC series (a) is increased in the order of FAAF-SMI > FP > FAAF-FP > SMI (Table S3). 


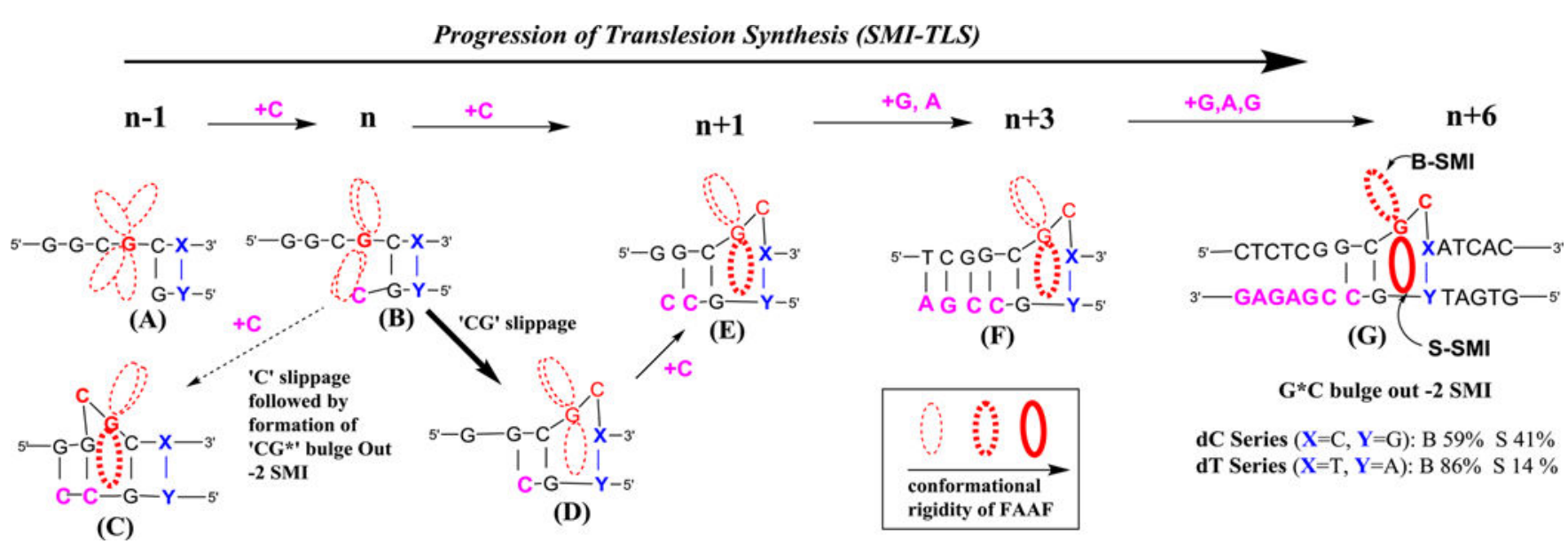

Figure 11.

Cartoon representation showing the conformational basis of AAF-induced -2 frameshift mutation. Incorporation of the correct dC opposite the AAF-modified $\mathrm{dG}(\mathbf{A} \rightarrow \mathbf{B})$ can lead to one- (C) or two-base (CG) slippage. The latter is preferred by AAF at $\mathrm{G}_{3}$ in the Nar sequence. Subsequent incorporation of $\mathrm{dC}(\mathbf{D} \rightarrow \mathbf{E})$ and $\mathrm{dG}$ and $\mathrm{dA}(\mathbf{E} \rightarrow \mathbf{F})$ can lead to a thermodynamically stable $-2 \mathrm{G}^{*} \mathrm{C}$ bulge-out structure, which ultimately produces a conformational mixture of S- and B-SMI $(\mathbf{G})$. Dotted ovals between $n-1$ and $n+3$ signify conformational flexibility within the confinement of syn or anti-glycosidic conformers. The inset illustrates the progressive nature of lesion conformational rigidity during TLS (i.e., light dotted $\rightarrow$ solid dotted $\rightarrow$ solid lines; see text). 


\section{옴

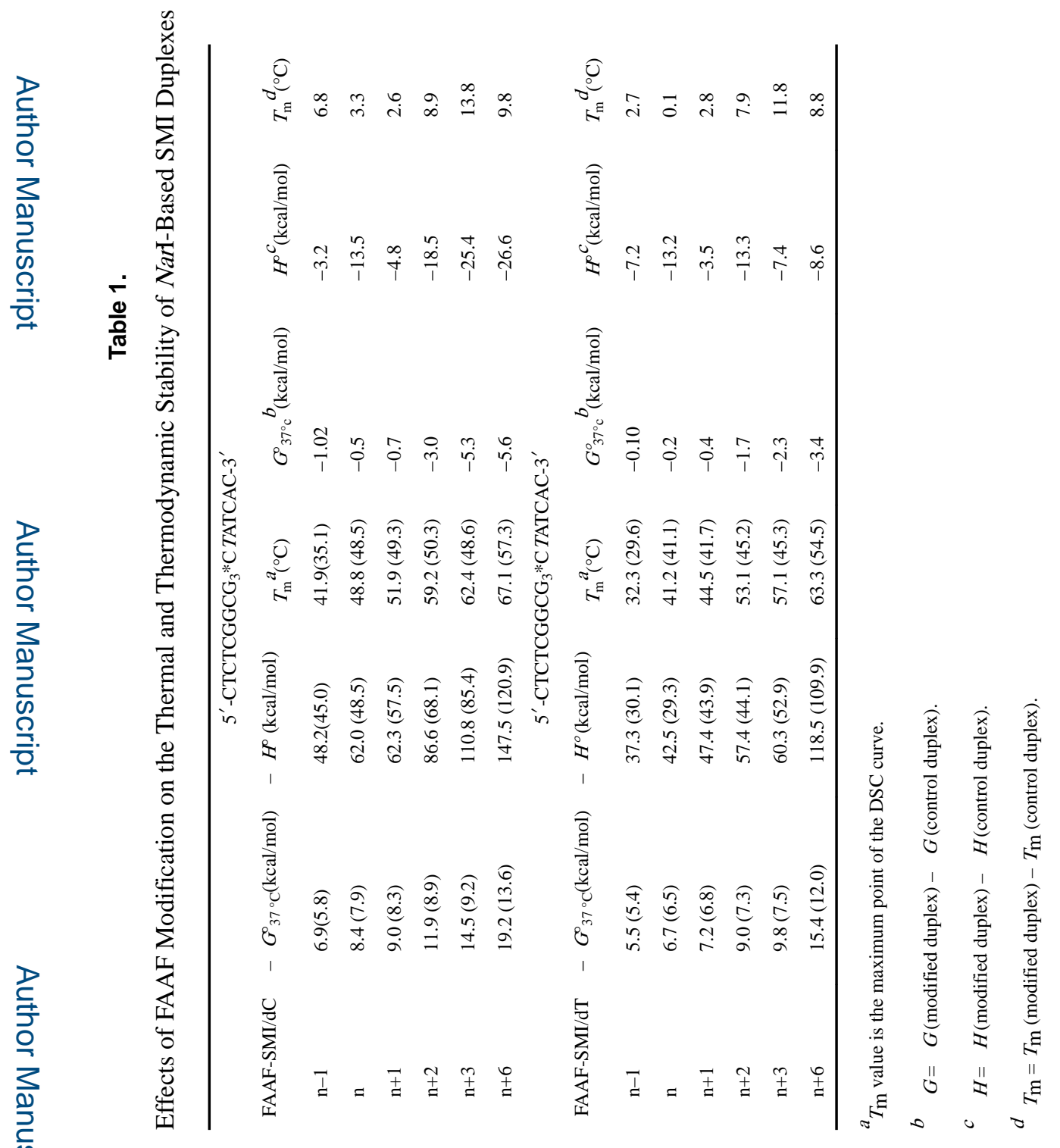

